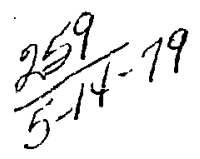

Lh. 2574

\title{
SEISMIC MONITORING: A UNIFIED SYSTEM FOR RESEARCH AND VERIFICATIONS
}

Lewis Thigpen

February 6, 1979

Work performed under the auspices of the US Department of

Energy by the UCLLL under contract number $W$ - 7405-ENG-48

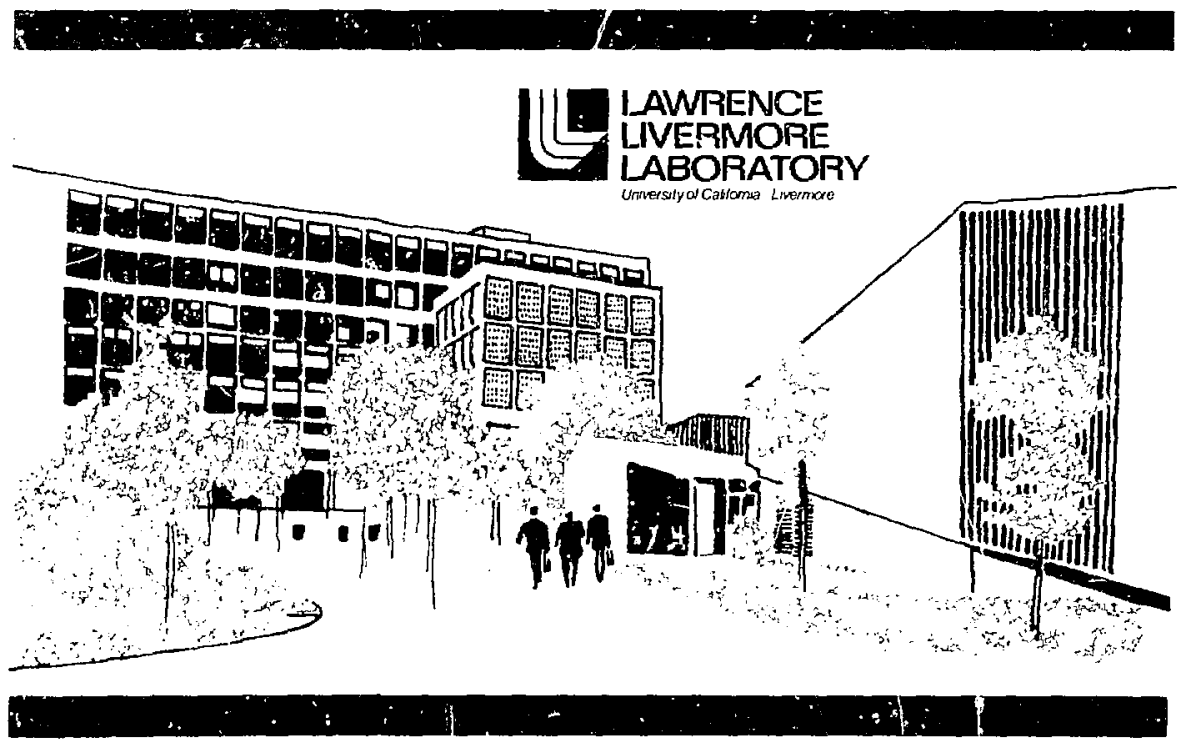




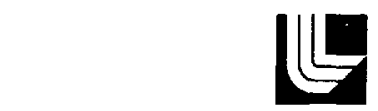

\section{AWRENCE IIVERMORE LABORATORY}

Iniversity of Caltorna Livermore Calfornia 94550

\section{UCRL-52665 \\ SEISMIC MONITORING: A UNIFIED SYSTEM FOR RESEARCH AND VERIFICATIONS}

Lewis Thigpen

MS. date: February 6, 1979 


\section{CONTENTS}

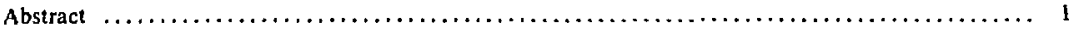

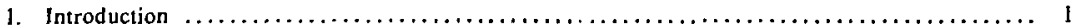

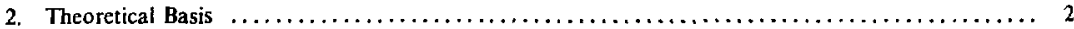

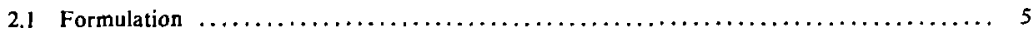

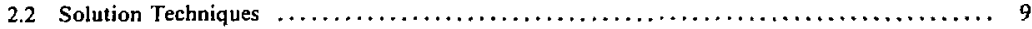

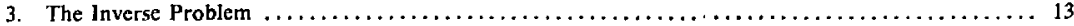

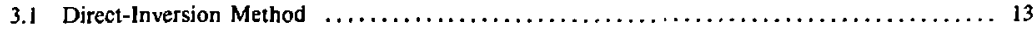

3.2 Trial-and-Error Method $\ldots \ldots \ldots \ldots \ldots \ldots \ldots \ldots \ldots \ldots \ldots \ldots \ldots \ldots \ldots \ldots \ldots \ldots \ldots \ldots 17$

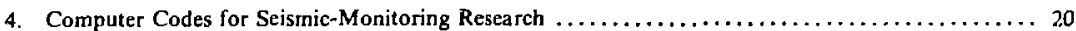

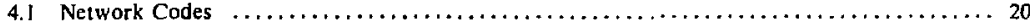

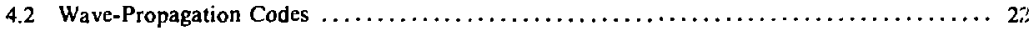

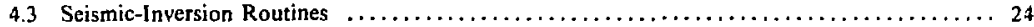

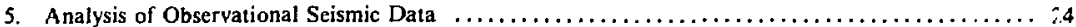

5.1 Analysis of a Single Seismogram $\ldots \ldots \ldots \ldots \ldots \ldots \ldots \ldots \ldots \ldots \ldots \ldots \ldots \ldots \ldots \ldots \ldots, 14$

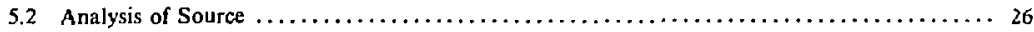

5.3 Construct Empirical Relations (Basic Rules) $\ldots \ldots \ldots \ldots \ldots \ldots \ldots \ldots \ldots \ldots \ldots \ldots \ldots \ldots 26$

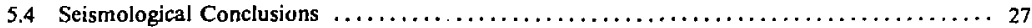

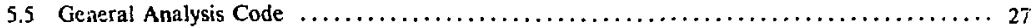

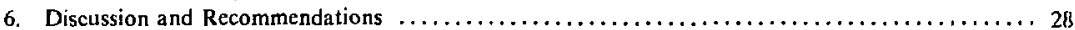

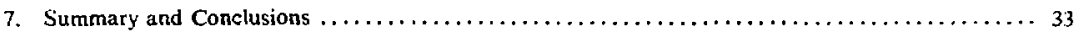

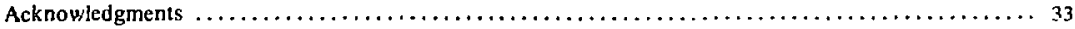

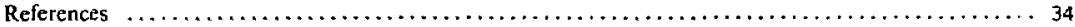




\title{
SEISMIC MONITORING: A UNIFIED SYSTEM FOR RESEARCH AND VERIFICATIONS
}

\begin{abstract}
I developed a system for characterizing either a seismic source or geologic media from observational data. This resulted from my examination of the "forward and inverse" problems of seismology. The system integrates many seismic monitoring research efforts into a single computational capability. Its main advantage is that it unifies computational and research efforts in seismic monitoring.
\end{abstract}

\section{INTRODUCTION}

During the last two decades considerable effort has been devoted to research projects necessary to iriprove techniques for monitoring underground nuclear explosions. These investigations have included development of seismic scaling laws ( $L$ tter et al., 1959; Romne), 195s; Weston, 1960; Werth and Herbst, 1963; Mueller and Murphy, 197I; Carpenter, 1967; Murphy, 1977; Peppin], 1977, studies on seismic coupling [Werth et al., 1962; Latter el al., 1961; Springer. 1966a, 1966b; Springer et al., 1968], and finite-difference calculations of the near-source behavior of explosions [Butkovich, 1965; Rogers, 1965; Holzer, 1966; Cherry, 1967; Cherry and Hurdlon', 1966; Cherry and Petersen. 1970; Schatz er al., 1977]. Within this period of time there has been considerable effort in developing empirical models for seismic-source function [Murphy and Mueller. 1971; Mc Evilly and Peppir, 1972; Aki, 1967; Akı el al., 1974; Randall, 1964, 197I; Backus and Mulcahy, 1976], on discrimination of earthquakes and cxplosions [Liebermann and Pomero], 1969; Morshall, 1970; Evernden et al., 1971: Marshall and Basham. 1972; Dotoglas et al., 1974], and on magnitude relations as a function of geophysical properties of the earth [Marshall et af., 1978; Chung, 1978]. While a large number of relationships has been derived analytically and from data, clearly a general framework is needed to unify the results. to provide predictions outside the range of current observations, and to develop a greater understanding of these observations.

The fundamental problem in seismic monitoring is to infer information about the source of seismic waves from the analyses and interpretations of seismograms. This is an inverse or systems identification problem; namely, the output of a system is approximately known over a time interval and its controlling parameters are not directly determinable. In seismic monitoring w wearch, it is thus necessary to construct mathematical models of the seismic intensity field (forward problem); to provide methods of solution to the inverse problem; and to interpret the estimated parameters in terms of the uncertainties, useful information content of the signal, and uniqueness of the solutions. The parameters to be estimated are (1) the common parameters of all the data, which affect the intensity cf seismic waves near and at distances from the source and (2) the individual parameters, such as hypocentral coordinates, origin time, energy or yield, and source mecha nism for eacil event.

Within the framework of these problems, numerous papers have been published on locating and identifying seismic sources [Flinn, 1965; Evernden, 1969, 1977; Lee and Lahr, 1975: Buland, 1976; Lomitz, 1977; Stoffa et al., 1974; Clayton and Wiggins, 1976; Dahlman and Israelson. 1977], on global and regional trave] times [Herrin and Taggert, 1962; Herrin, 1968; Evernden, 1967; Ryabay, 1977; Schaffer et al, 1977; Nersesov and Rautian, 1977; Sollogub and Chekunov, 1978], and on noise [Frosch and Green, 1966; Molnar er al., 1969]. Studies have also been made on the dynamic properties of the source as gbserved along different transmission paths and on generalized inverse problems. A comprehensive list of references on these subjects is contained in the review articles of Richards (1975), Anderson (1975). Engdahl et al. (1975), and Archambeau (1975). Also, the report $C C D / 558$ (1978) contains a comprehensive list of relations derived from the above studies. 
The objective of my present work is to review the seismic forward and inverse problems in the context of seismic monitoring. to outline a computational capability (including a list of available sub-programs) for these problems, and to propose research areas. The second section presents a form llation of the wave proşagation problem (forward problem) and a discussion of solution techniques. In Section 3.1 show how the inverse problem can be formulated to account for the statistical nature of the measurements. Computer codes used to solve the forward and inverse problems appear in Section 4 . The natural sequence of a nalysis for seismic data is described in the fifth section. In Section 6.1 iuggest ways to use the methods described in Sections 2 and 3 in seismic monitoring research. Finally a summary and conclusions are in the last section.

\section{THEORETICAL BASIS}

Transient disturhances (seismic waves) emanating, from explosive and earthquake sources provide a large quantity of information about the source mechanis:n and mechanical properties of the earth. Ground motion associated with these disturbances takes the forn' of elastic waves propagating in a "spherically symmetric" earth. As the wavefront expands, the radiation pattern becomes progressively distorted duc to free surfaces and the structural and intrinsic material preperties of the earth. The original pattern belore distortion depends intimately on the physical mechanism responsible for the initiation of these disturbantes as weil as on the propertics of the media in the immediate vicinity of the suurce [Sharpe. 1942; /volinskii. 1960; Westem. 1960).

Ground motion from the detonation of an undergrotind nuclear explosion is a complex physical phenomenon (Fig. 1). When a nuclear explosion is detonated all of its energy is released in less than $z \mu \mathrm{s}$ [Bukouich and lewis. 1970]. The high pressures and temperatures generated by this high-energy density form al strong shock wave that propagates into the surrounding rnediure. This shock wave yaporizes the device container and some of the surrounding rock, forming a vapor-filled cavity [Rotean, 1971]. Cavily growth is generally assumed to be spherical; however, calculations indicate that nearly spherical cavitics are formed only when nuclear detonations occur at sufficient depths or in strong dry rock [Burkewith, 1971]. However, most analyses of this process assume spherical wave propagation [Sharpe, 1942; Zudinski, 1960; Cherry and Putersen. 1970; Schatz, 1974]. This cavity expands to a volume in which the pressure within the cavity is in equilibrium with the stress in the cavity wall. Further out, where tile energy in the shock is too low to vaporize the material, melting otcurs. A region of plastic fow follows and terminates when the stresses fall below the elastic limit of the rock. Elastic wave propagation hegins at this pcint. The complete process may be modeled by a complex system of nonlinear equations [Sihatz, 1974; Schat: et al., 1977; Burton and Schotz. 1974].

Unlike explosions, earthquakes do not approximate spl ericaily symmetrical radiators. The data showing this are the directions of the first motions on seismogra ns from an earthquake recorded at many stations distributed over the earth. 'The physical concept of elastic-relound theory as proposed by Reid [Benioff. 1964] is generally accepted as the mechanism for a tectonic earthquake. The cssence of this hypothesis as pointed out by Archuleta and Frazier (1978) is that tectonic stress in a rcgion is relaxed as a shearing fracture spontaneousiy spreads over a finite zone (the fault). The rate of growth and the fracture geometry result from the state of stress in the medium before rupture, the instantaneous stress in the medium during rupture, a fracture criterion determining whether or not the rupture front advances, and the prior history of the material. This process is depicted in Fig. 2 (after Benioff, 1964). Long before the earthquake occurs, the situation is as shown in Fig. 2a. Immediately before the earthquake the material surrounding the fault is deformed (Fig. 2b). In Fig. $2 \mathrm{c}$ slip has just begun, as indicated by the arrows; this thereby increases the stresses in the neighboring regions of the fault and results in a rapid progression of the faulting process to attain the position indicated in Fig. 2d. Seismologists usually represent this source as a stress-displacement discontinuity over an internal surface [Harkrider, 1964; Hudson, 1969a; Kennetl. 1974].

The forward-vave propagation problem provides the theoretical basis for securing a rational picture of the initiation of the "elastic" seismic waves described above and of obtaining an understanding of effects of the conditions at the focus and along the propagation path on $s r^{\circ}$ mograms. This problem is solved by deriving 


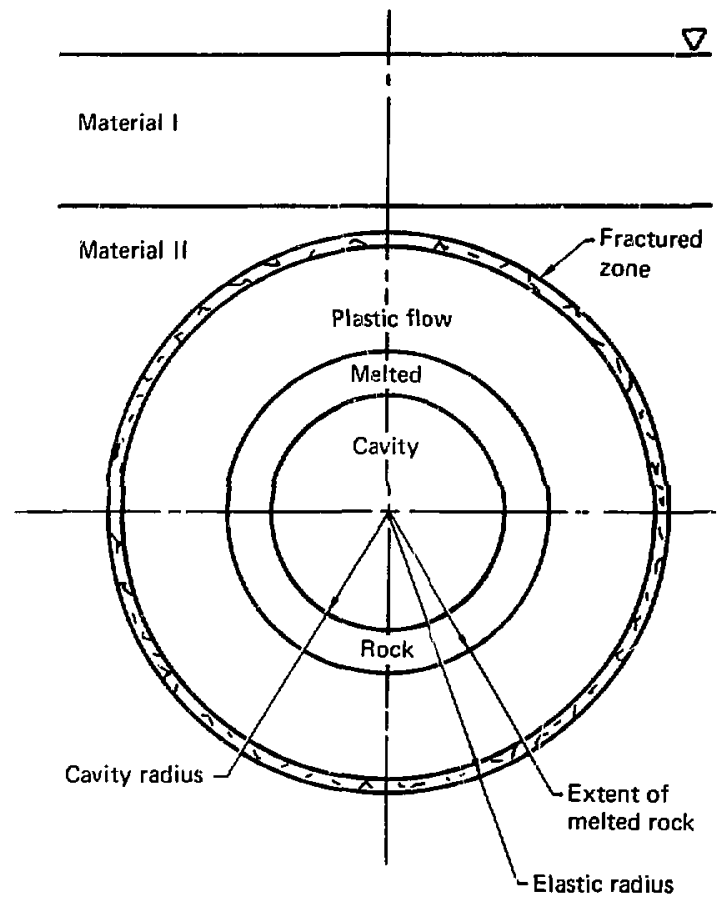

FIG. 1. Material deformation in region surrounding an explosion.

a functional relationship to predict the theoretical response for all input to a particular geophysical earth model, Fig. 3, for example. The functional relationship for nearly all models that approximate the earth may be stated as:

$$
\mathbf{u}=\mathbf{F}(x, t ; \alpha, s),
$$

where $u$ is a vector whose components represent the values of some geophysical relevant quantity. F is a vector function of $\alpha$ containing the model parameters, of the source parameters $s$, and of the independent variables of the system $x$ and $t$. The function $F$ is derived from the solution to wave propagaion prolslems. Thus its representation depends on the method used to solve the governing field equations with appropriate boundary and initial conditions. Hence, it may be tabular, in the form of curves, or an analytic function.

For my example (Fig. 3), the model parameters 0 : are the $n$-layer $P$ - and 5 -wave velocities and densities $\alpha_{R}, \beta_{R}$, anć $\rho_{R}(\ell=1, n)$, respectively, and the $n-1$ layer thicknesses $h(\ell=1, n-1)$. Thus there are $M$ components of $\alpha$, where $M=4 n-l$. The system parameters $x$ and $t$ are the coordinates $r, \theta$, and $z$ and the time $t$. The source is characterized by $f\left(x^{\prime}, t ; s\right)$, where $x^{\prime}$ are the conrdinates of the source ard $s$ are the parameters characterizing it. 


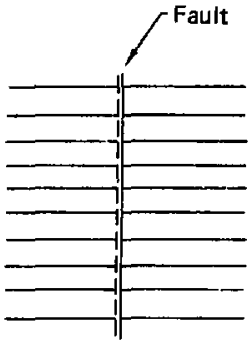

a

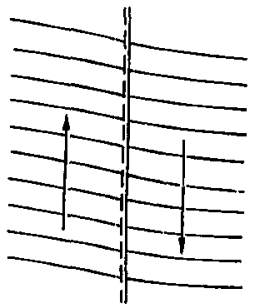

b

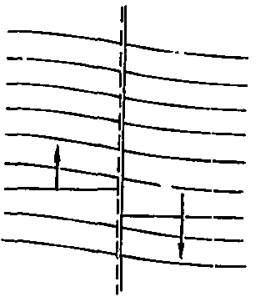

c

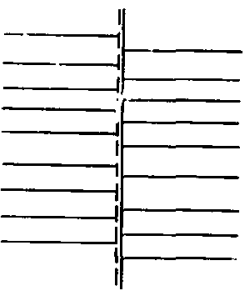

d

FIG. 2. Reid's elastic-rebound earthquake source mexhanism.

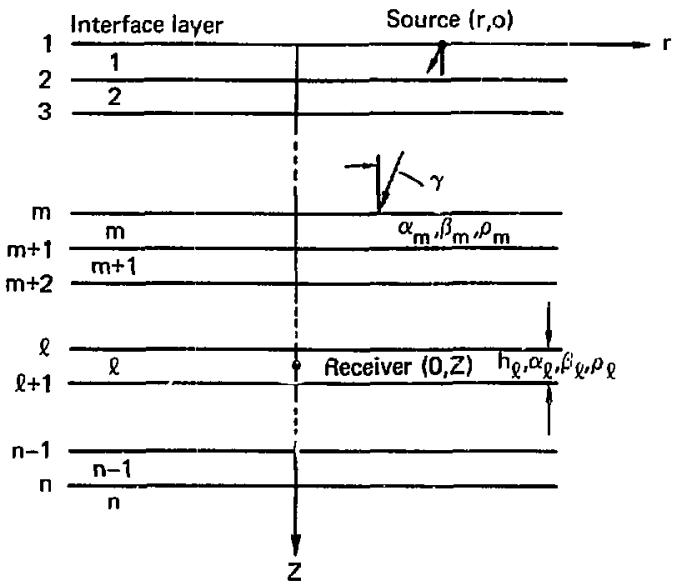

FIG. 3. Geometry and nomenclature for wave propagation in a layered elestic halfspace, from explosive source at surfice and receiver below surfare. There is nothing critical atout this representation. Source and receiver can be placed anywhere in medium. To account for anelarticily, added model parameters, $Q_{\alpha m}$ and $Q_{\beta m}$, are included for each layer. 
A nuclear explosive source may be modeled as a region of gas with a given internal energy content [Sihatz, 1973, 1974]. In this case, the source parameters s are given by the internal energy content $\epsilon$ and the radius of the source $R_{s}$ for spherical sources. If the source is characterized as a pressure profile on a boundary, the parameters contained in vector $\mathbf{s}$ may be the peak pressure $\mathbf{P}_{0}$, the overburden pressure $\mathbf{P}_{c}$. and the attenuation coefficient of the pressure-time profiles, $\beta$ [see, for example, Sharpe, 1942; Mueller and Murphy, 1971]. For an earthquake source modeled as a stress relaxation over a finite fault, the source vector $\mathbf{s}$ contains the geometry of the fault plane (for a rectangular fault, its length $\mathbf{L}$ and width $W$ plus orientation), the rupture velocity $\mathrm{V}$, the initial stress in the medium $\sigma_{1}$, and the coefficient of sliding friction $\mu$ [Archuleta and Frazier, 1978]. For earthquakes modeled as point-source dislocations the source may be represented by moment tensors and a dislocation time function [Kanamori, 1970; Randall, 1971; Helmberger, 1974; Langston and Helmberger, 1975; Backus and Mulcahy, 1976]. Below I discuss the formulation of the wave propagation problem (forward problem).

\subsection{FORMUI.ATION}

Presently no general system exists for computing the response of geologic materiais for all ranges of interest from a general source. Thus material behavior has a different representation in different regions (Fig. l, for example). The system of field equations governing the motion of a particle in a continuum comprises the equations of conservation and appropriate constitutive equations. These field equations are subject to initial and boundary conditions. The equations of conservation and irreversibility in Cartesian tensor notations are

$$
\begin{aligned}
& \frac{\partial \rho}{\partial t}+\frac{\partial}{\partial x_{i}}\left(\rho V_{i}\right)=0, \\
& \frac{\partial V_{i}}{\partial t}+V_{j} \frac{\partial V_{i}}{\partial x_{j}}=\frac{1}{\rho} \frac{\partial}{\partial x_{j}}\left(o_{j i}\right)+b_{i}, \\
& \frac{\partial \epsilon}{\partial t}+V_{i} \frac{\partial \epsilon}{\partial x_{i}}=\frac{1}{\rho} a_{i j} \frac{\partial V_{i}}{\partial x_{j}}-\frac{1}{\rho} \frac{\partial h_{i}}{\partial x_{i}}+q,
\end{aligned}
$$

and

$$
\frac{d S}{d t}>-\frac{1}{\rho} \frac{\partial}{\partial x_{i}}\left(\frac{h_{i}}{T}\right)+\frac{q}{T}
$$

These equations hold for any continuum. Here $V_{i}$ are the components of the particle velocity, $\rho$ is the mass density, $\sigma$ is the symmetric Cetuchy stress tensor, $b_{i}$ are the components of the body force per unit mass, $\epsilon$ is the internal energy per unit mass, $h$ is the heat flux vector, $q$ represents an energy source, $S$ is the entropy, $T$ is the temperature, $x$ is the position vector, and $t$ is the time. The system [Eqs. (2) through (5)] contains more unknowns than equations To complete the system, additional equations, called the constitutive equations, representing the intrinsic properties of the materials are required.

Investigations to develop thesc constitutive relations for geologic materials have been a considerable part of the effo:t in seisrnic-monitoring research [Butkrwick, 1967, 1973; Cherry et al., 1975; Costantino and Shock, 1976; Costansino, 1978; Schatz et al., 1977; Burton et al., 1977]. The ability to model the physical behavios to peological materigls undtiz extreme loadings rests on the applicability of constitutive equations to r.present the intrinsic properties of the meteriais under consideration. These equations represent idual materials and inust satisfy certain constraints: frame-indifference and equipresence. They must also be 
consistent with conservation laws and the principle of irreversibility. Frame-indifference places restrictions on the possible functional dependence of stress on deformation history. Equipresence guarantees reciprocity of action; i.e., if mcchanical processes affect thermal processes, then the reverse must also be assunied true unless proved otherwise. Any admissible history can be made to satisfy conservation principles by suitable choiccs of the body force $b$ and the heat source $q$. The principle of irreversibility places restrictions on the forms of the constitutive equations. Modeı $\urcorner$ continuum mechanics has provided a framework for constructing these rclations. which contain arbitrary material functions to be evaluated empirically from experimental data [Eringen, 1962]. Yet, practicality severely limits the details of material behavior that can be included in these equations, and gross assumptions are usually made to formuiate a mathematically tractable problem.

In formulating the wave propagation problem induced by a nuclear explosion one assumes that a finite amount of energy is released in an infinitely conicntrated form instantaneously $(t=0)$, which sends out a strong shock wave into the surrounding medium (Fig. 1). Time scales are assumed to be such that transport processes have a negligible effect on the transfer of energy in the wave. Hence adiabatic processes are assumed to occur throughout the medium. In regions where the eviergy in the wave is greater than the energy required for vaporization $\epsilon_{v}$, a gaseous filled cavity is formed. These gases are assumed inviscid and hence cannot support shear stresses. The resulting stress tensur becomes isotropic and gives a measure of the pressure within the cavity. Since the material within the cavity contains a considerable amount of heat, the constitutive equations reduce to an equation of state involving pressure, density, and internal energy for the expansion of the gascs within the cavity. Equation (5) shows that the entropy remains constant throughout for all time $t>0$ with no additional heat sources. With these assumptions, the field equations governing the motion of the gases within the cavity bocome

Hydrodynamic Region, $\epsilon>\epsilon_{v}$

$$
\begin{aligned}
& \frac{\partial \rho}{\partial t}+\frac{\partial}{\partial x_{i}}\left(\rho V_{i}\right)=0 \\
& \frac{\partial V_{i}}{\partial t}+v_{j} \frac{\partial V_{i}}{\partial x_{j}}=\frac{1}{\rho} \frac{\partial P}{\partial x_{i}}+b_{i}, \\
& \frac{\partial \epsilon}{\partial t}+V_{i} \frac{\partial \epsilon}{\partial x_{i}}=\frac{1}{\rho} P \delta_{i j} \frac{\partial V_{i}}{\partial x_{j}},
\end{aligned}
$$

and

$$
f(P, \rho, \epsilon)=0,
$$

where $\delta_{\mathrm{j} j}$ is the $\mathrm{K}$ ronecker delt $c_{\mathrm{i}}$ and $\mathbf{P}, \rho$, and $\epsilon$ are the measurable state variables representing pressure, density, and internal energy, respectively. Continuity of pressure, velocity, and interral energy is required at the boundary of the cavity and serves as input to the finite-strain plasticity region.

\section{Finite-Strain Plastic Region}

This region includes the regions bet ween the vapor-filled cavity (hydrodynamic region) and the elastic boundary (Fig. 1). This is the most complicated region of the problem to model, In part of this region, the internal energy lies between that required to vaporize the material, $\epsilon_{v}$, and that requircd to melt the material, ef. Further, the stresses are above the elastic limit throughout this region. It is not well understood how to model the nonelastic processes oecurring in this region, and many gross assumptions are assumed. Schatz (1973, 1974), Burron and Schatz (1974), and Burton el al. (1977) discuss the assumptions used in the SOC and TENSOR 
codes for formulation of the wave propagation problem in geologic media. In their formulation, the melting phenomenon is treated using the same form of constitutive equations used in the solid region. Melting and subsequent unloading are assumed adiabatic. 'The material is assumed to melt if the internal energy $\epsilon$ is greatcr than that required for melting $\epsilon_{f}$. If $\epsilon_{f}<\epsilon<\epsilon_{\mathrm{y}}$, the shear modulus and shear stress are set to zero. If the internal energy drops below the melt energy during unloading. the material returns to the solid state. It must be emphasized that precise models for the nonlinear behavior of rack under shock loading have not been develoned.

In the region where the material behaves as a solid, the constitutive model is formulated using approximations from metal plasticity. The material is assumed to behave as an elastic-viscoplastic material. Loading is initially assumed to be incrementally elastic. A yield or failure surface serves to establish whether the material has deformed plastically or has fractured. S Iress states above this surface are not allowed, and the stress deviators are adjusted to cause the state of stress to lie on this or on some equilibrium surface. The stress adjustment gives rise to irrecoterable strain. This may be th the form of plastic flow or the opening of cracks or voids. The stress adjustment or flow rule assumes that plasuc strains are normal to the yield surfacc. This idea was taken from metal plasticity, which assumed no inelastic volume deformation, an adequate condition for many structural materials. However, this assumption is not adequate for most geologic materials, and inelastic volume deformation is allowed by prescribing a mean stress-volume relation taken from measurements on laboratory samples. The field equations for this region are thus written

$$
\begin{aligned}
& \frac{\partial \rho}{\partial t}+\frac{\partial}{\partial x_{i}}\left(\rho V_{i j}\right)=0, \\
& \frac{\partial V_{i}}{\partial t}+V_{j} \frac{\partial V_{i}}{\partial x_{j}}=\frac{1}{\rho} \frac{\partial \sigma_{i j}}{\partial x_{j}}+b_{i}, \\
& \frac{\partial \epsilon}{\partial t}+V_{i} \frac{\partial \epsilon}{\partial x_{i}}=\frac{1}{\rho} \sigma_{i j} \frac{\partial V_{i}}{\partial x_{j}}, \\
& P=-\frac{1}{3} \sigma_{k K}=\left\{\begin{array}{l}
f(\rho, \epsilon), \epsilon>\epsilon_{\mathrm{f}} \\
f(\rho), 0<\epsilon<\epsilon_{\mathrm{f}}
\end{array},\right. \\
& \frac{d \hat{S}_{i j}}{d t}=2 \mu \bar{d}_{i j}+\zeta S_{i j},
\end{aligned}
$$

and the yield surface is given by

$$
\mathrm{g}\left(\mathrm{S}_{\mathrm{ij}}, a_{k \kappa} ; k\right)>0,
$$

where

$$
\begin{aligned}
& \frac{d \hat{S}_{i j}}{d t} \equiv \frac{\partial S_{i j}}{\partial t}+\frac{\partial S_{i j}}{\partial x_{m}} V_{m}+S_{i m} W_{m j}-S_{m j} W_{i m}, \\
& \bar{d}_{i j} \equiv \frac{1}{2}\left(\frac{\partial v_{i}}{\partial x_{j}}+\frac{\partial v_{j}}{\partial x_{i}}\right)-\frac{1}{3} \frac{\partial v_{k}}{\partial x_{k}} \delta_{i j},
\end{aligned}
$$




$$
S_{i j} \equiv o_{i j}-\frac{1}{3} o_{k K} \delta_{i j}
$$

and

$$
w_{i j} \equiv \frac{1}{2}\left(\frac{\partial V_{j}}{\partial x_{j}}-\frac{\partial V_{j}}{\partial x_{i}}\right)
$$

$\sigma_{i j}$ is the Kronecker delta, $\mu$ is the shear modulus, and $\zeta$ is a proportionality factor. The co-rotational deviatoric stress rate $\left(\mathrm{d} \hat{\mathrm{S}}_{\mathrm{ij}} / \mathrm{d} t\right)$ is used to maintain material objectivity. Its representation is not unique, and different representations require different forms for the material constitutive coefficients. The material functions, $f(\rho, c)$, $\mu$, and $\mathrm{g}\left(\mathrm{S}_{\mathrm{ij}}, \sigma_{\kappa \kappa} ; \kappa\right)$, are usually determined from quasi-static compression experiments [Schatz, 1974; Schatz et al., 1977]. In a series of papers, Larson and co-workers [Larson and Rodean, 1975; Lorson, 1977a, 1977b; Larson and Anderson, 1978; Anderson and Larson, 1976, 1977] have discussed the applicability of using quasi-static experiments for determining constitutive relations for geologic materials. In their work, they used shock wave experiments in both plane and spherical geometry to test rate effects in several geologic materials. They pointed out that some materials (Westerly granite and Nugget sandstone) exhibit sume quasi-static features consistent with shock wave data. However, they observed that other highly porous materials exhibit time dependent behavior unüer shock loading, behavior not present under quasi-static conditions. These effects result from pore collapse, phase changes, chemical reactions of mineral constituents with pore water, etc., under shock loading. Under these conditions, quasi-static measurements are not sufficient to describe the phenomenological coefficients arising in the constitutive equations. Presently no constitutive theory is avaijable to adequately describe these rate effects,

\section{Elastic Region}

Stresses and velocities are continuous across an elastic plastic boundary. This connects the elastic and plastic states. When the stresses fall below the yield point of the material, $g\left(S_{i j}, a_{\kappa \kappa} ; \kappa\right) \leqslant 0$, elastic behavior follows. The field equations are thus

$$
\begin{aligned}
& \frac{\partial \rho}{\partial t}+\frac{\partial}{\partial x_{i}}\left(\rho V_{i}\right)=0, \\
& \frac{\partial V_{i}}{\partial t}+V_{j} \frac{\partial V_{i}}{\partial X_{j}}=\frac{1}{\rho} \frac{\partial \alpha_{i j}}{\partial x_{j}}+b_{i},
\end{aligned}
$$

and

$$
\sigma_{\mathrm{ij}}=\mathrm{C}_{\mathrm{ijk \Omega}} \mathrm{e}_{\mathrm{ke}} \text {, }
$$

where $C_{i j k g}$ are the elastic coefficients. Symmetry of the stress and strain tensors and the existence of a strain energy density function re.trict the fourth order tensor $C_{i j k e}$ to 21 independent components. For isotropic materials, the tensor is further reduced to the two Lame parameters $\lambda$ and $\mu$. For isotropic materials Eq. (22) becomes

$$
o_{i j}=\lambda e_{k k} \delta_{i j}+2 \mu e_{i j} .
$$


For small displacemeni gradients, the strain tet. or is defined

$$
e_{i j} \equiv \frac{1}{2}\left(\frac{\partial u_{i}}{\partial x_{j}}+\frac{\partial u_{j}}{\partial x_{j}}\right),
$$

where $u$ is the displacement vect.sr. The material parameters $C_{i j k x}$, or in the isotropic case $\lambda$ and $\mu$, are determined from laboratory and field measurements.

\section{Roundary Conditions}

The boundary conditions are represented in the form of surface tractions or particle displacements or both. At material interfaces one requires continuity of stress and displacements, and free surfaces are required to be stress free.

For the solution to problems in an infinite domain it;;:-al reasons place certain restrictions on the behavior of the wave field at infinity. If sources are confined in a finitt region, one demands that thr re exist no wave propagating from infiniry back inio the medium. This physical resiraint requites that the suluion be regular and that it satisfy the Sommerfeld radiation condition at infinity [Eringen and Suhubi, 1975]. For wave propagation in a spiterically symmetric medium, one requires reguiarity of the solution at the center of symmetry.

For earthquake sources, the region surrounding the fault (elastic-rebound hypothesis) is usually assumed to be a linear elastic material. In many studies on wave propagation in geologic media, the erth is approximated as a linear viscoelartic solid [Hart el al., 1977; Kancmori and Andersnn, 1977]. Hence, the governing field equations are then represented by the linearized form of Eqs. (20) through (22), and the correspondence principle between elastic and viscoelastic media applies. Assuming arelastic media, two additional material paraneters, $Q_{o m}$ and $Q_{\beta m}$, for each layer (Fig. 3) are necessary to account for atienuation and dispersion. The motion is initizted by a discontinuity in displacement along the fault.

The explici: form of the sets if Eq. (6) through(9), (10) through (15), and (20) through (22) presently usec to study wave $\mathrm{g}$ ropagation in geologic materials $\mathrm{fr}_{1 \mathrm{r}}$ explosive sources is contained in the tvorks of Maenchen and Sack (1964), Cherry and Petersen (1970), herry et al. (1970), and Schatz (19?3, 1974). Archuletta and Frazier (1978) present a formulation (containing the measurable source parameters) for the computation of the near-field response resulting from an earthquake. The formulation for wave propagation in linear elastic media resulting from equivalent elastic sources (point body force or moment tersor representations in elastic media) is well represented in the literature [Harkrider, 1964; Utimberger, 1974; Hudsan, 1969a, 1969b: Chapman and Phinney, 1972; Richards, 1971, 1973; Randall, 1964; Johnson, 1974; Barkus and Mfidcahy, 1976; Eringen and Suhwbi, 1975].

\subsection{SOLUTION TECHNIQUES}

Most solutions of pracical importance in elastodynamics that can be represented in closed form are contained in the works of Eringen anc Suhwbi (1975) and Keller and :apadakis (1977). In most practical cases with complex geometry, numerical integration techniques are necessary. Existing methods for solving the sets of Eas. (6) through (9), (10) ihrough (15), and (20) through (22) are the integral-transform inethods, the finite-difference and finite-eientent methods, and the method of characteristics. I shall begin my discussions with the integral-transform methods.

The integral-transform approach involving complex variatles (e.g., Cagniard-de Hoop [Abramovici, 1978] or spectral method) is only suitaóle for boundary-value problems with transverse homogeneity. Numerical values are only available for certain reginns of the solution domain. Tine main disadvantage of these approa thes is that they are limited to linear solids and in man" $c_{v}$ es $t_{v}$ :-vo space dimensions. Hence, these methods are restricted to infinitesimal strains and cannot be used in ti:e near-source region (regions represented by nonlinear constitutive equations). However, because the earth is almost always approximated by a multilayered linear elastic solid away from the source, integral-transform methods are widely used in studies of theoreticul seismology. 
Integral-transform methods arc used in the interpretations of seismic observations and in providing the functional relationships [ $\mathrm{Eq}$ - ( 1 )] for inversion studics. These methods ase applicable for wave propagation studies in laterally homogeneous media. In a major series of papers [He/mberger and Wiggins, 1971; //elmberger, 1972, 1973a, 1973b; Wiggins and Helmberger, 1973, 1974; Mitchell and 'telmberger, 1973; Helmberger. 1974; Helmberger and Engen. 1974], Helmberger and his colleagues used generalized ray theory (Cagniard-de Hoop method) to derive a detailed pieturc of seismic velocities in theearth by comparing synthetic seismograms with observational seismic records. In practice the Cagniard-de Hoop method takes account of a small subset of multiples (reverberations) present in a layered structure.

If all possible multiples are to be retained, computation in the frequency domain appears more appropriate. Such a procedure originally studied by Fuchs and termed the reflectivity method [Fuchs and Muller. 1971] has been applied by Miiller (1973) to study the eartin's core. The method uses matrix analysis of plane wave reflection coefficients within the layering, a numerical integration over horizontal-wave number (or ray parameter) to recover the cffect of a particular point source and a subsequent inverse Fourier transform over frequency. In Table 1, I compare the advantages of the generalized ray theory and the reflectivity method.

Chapman and Phinney (1972), Richards (1973), and Choy (1977) give an extensive account of seismic wave theory in a spherically symmetric earth. This method has been successfully used to construct long-period seismograms of core phases in the distance range 100 to $125^{\circ}$. Their approach is similar to the Cagniard approach in identifying a particular ray; it is also similar to the reflectivity method since the soletion is obtained in the frequency domain. Hudson (1969a, 1969b) presents a similar formulation for studying both body and surface waves in a layered medium in cylindrical coordinates in the distance range 30 to $100^{\circ}$. In two recent papers, Keller and Papadakis (1977, Chapter 11) and Chapman (1978) discuss the similarities of these approaches. Their papers should be consulted for a clcar understanding of these ana!ytical methods.

First-motion approximatior.5 to the techniques have been discussed by Chapman (1976), Wiggins (1976), and Mellman in/ Helmberger (1978). The approximations of Chapman and Wiggins are nearly as fast in computation as thcse for asymptotic ray theory and at the same time preserve the accuracy of fullwave techniques. Approximations for head waves are only adequate at high frequencies. Mellman and Helmberger show that their modified first-motion approximation gives (1) accurate results, compared with the Cagniard-de Hoop method, for generating synthetic seismograms for problems involving a homogeneous sphere and (2) a triplication in a realistic earth model with considerable saving in computer time.

TABLE 1. Comparisors of generalized ray and rellectivity integral-transform techniques.

\section{Generallaed ny theory \\ Advantrges}

Disadvantages

Reflectivity technique

Advantages

Disadvantages
Inclusions of fret-surface reflections

Since calculations gre made in time domain it is easł to restrict time interval of interest

Separate Cagniard paths have to be found for each kinenitaite group for each distance $X$ Problems in ray selection. Difllcult to assess importance of multiples and mode conversions

For reflectivity zone, all muliples and inter-conversions are included or a preseribed subset of these multiples is included

Main computational cost comes in setting up reflectivity response. It is then relatively inexpensive to consider many distances

Neglect of free-surface reflected paths and coupling between upper and lower part of layering" Cost of setting up reffectivity response is considerable. Hence method is not efticient for computing seismograms at a few dlstances from source

Kennet( (1974) has improved this technlque to allow for reverberattve structures and for the effect of free surfaces by using an iterative scheme to calculate transmission and reffection coefflcients. 
The methods ciscussed in the preceding paragraphs mainly concern calculations of body waves. Suppose that the transformed response for the methods diseussed above can be written

$$
\hat{u}(\omega, P)=\frac{N(\omega, p)}{D(\omega, p)}
$$

Surface waves come from poles of Eq. (25) [Lapwrod, 1949]. That is, from solutions of

$$
D(\omega, p)=0 .
$$

Typically. Eq. (26) has many solutions, $P_{i}$. The surface-wave contribution to the seismogram may be written [Chapman. 1978]

$$
u(t, x)=-\frac{1}{\pi} \frac{d}{d i}-R_{e} \int_{0}^{\infty} \frac{N\left(\omega, P_{j}\right)}{\left[(\partial D / \partial \rho)\left(\omega, P_{j}\right)\right]} \exp \left\{i \omega\left(P_{j} x-t\right)\right\} d \omega .
$$

Numerous methods exist in the literature for evaluating the surface-wave response given by Eqs. (25) or (27) [sec. fo example. Haskell. 1953; Hiudson. 1969b; Harkrider. 1964; Schwab and Knopoff. 1972]. In the above cquation., $p$ is the ray parameter and $\omega$ is the frequency.

Harkrider (1964). Sihu'ah and Knopoff (1972), Satio (1967), and Takeuchi and Saito (1972) present comprehensive discussions on the catculation of surface waves and free-mode periods of attenuation. Kanamori (1970) has used the synthesis of long-period surface waves to determine souree parameters. Gilbert and his colleagues, in a scries of papers. have used free oscillations of the eariti's normal modes to retrieve the seismic moment tensor [Gilhers. 1971 a; Dziewanski and Gilhert. 1974; Buland and Gilhert, 1976; Gilhert and Buland, 1976] and to resolve the structure of the earth [Backus and Gilhert, 1968; Gilbert, 197Ib; Johnson and Gilherl, 1972].

Hermann and Nutlli (1975a, 1975b) have used surface-wave theory at regional distances to successfully model ground motion for an earthquake source in a continental interior. They found excellent agreement betwcen predicted and observed maximum verticai component $\mathrm{L}_{\mathrm{g}}$ ground velocities and accelerations in the 2- to 3-s period range over a distance range of 100 to $2000 \mathrm{~km}$.

Swanger and Boore (1978) used summation of surface-wave modes in a layered half-space to simulate strong-motion displacements from the 1968 Borrego Mountain earthquake. It must be pointed out that superposition of surface-wave modes gives an incomplete description of motion. However, for shallow sources in typical earth structures, surface waves dominate the ground motion at distances on the order of tens of $\mathrm{km}$ and at periods of greater than 1 or $2 \mathrm{~s}$ [Hamann and Nuttli, 1975a, 1975b].

Thus synthetic seismogram construction using mode superposition has a number of attractive features:

(1) Details of the method have been worked out and efficient programs to compute basic dispersion parameters are readily available.

(2) The dispersion parameters and eigenfunctions need only be computed once for the layered model to permit time-domain synthesis for any type and depth of source, azimuth, or epicentral distance.

(3) The time-domain synthesis is simple in practice and the cost is negligible in most cases.

(4) The separation of source and media dependencies of the response allows for interpretation of the relative importalise of source depth and near-site structural response.

(5) It is easy to extend point-source solutions to those for extended sources.

(6) The number of layers is not a practical limitation as in generalized ray methods. Here all reverberations are included. 
The main drawback of mode superposition is that it gives only an approximation to the total motion. Presently, no quantitative measure of the adequacy of the approximation exists [Swarger and Boore. 1978]. Other disadvantages ef mode superposition are when no sufface layer exists, in this casc no $S H$ normal modes, and when the source is so deep relative to the epicentral dislance that the motion is dominated by energy with high horizontal-phase velocities [Swange' and Broser, 197\%]. Other techniques using the full response must be used in these cases, e.g.. the reflectivity techrique as extended by KenneII (1974).

Finite-difference and finite-element approaches are considered to be versatile means for solving gencral wave-propagation problems. The techniques are especially suited for solutions to problem: with nonlinear constitutive equations. The methods have been exclusively uaed for calculations in the immediate vicinity of seismic sources [Bukovich. 1965; Holzer, 1966; Cherry and Petersen, 1970; Bryan et al. 1978; Archuletla and frazier. 1978], for wave propagation in laterally heterogeneous media [1,35mer and Drake, 1972; Beore, 1972; Smith, 1975], and for studying the eflects on wave propagation in media departing from isotropic linear elasticity [Garg, 1971; Andrews and Shlien. 1972; Schatz et al.. 1977]. These techniques integrate the difference approximation of the hasic differential equations direetly.

Their main disadvantages are (1) their inability to represent discontinuitics inberent in the solution of the governing equations (thus one needs a prohibitive number of spatial increments for adequate resolution) and (2) the use of artificial viscosity to prevent ringing. The Jatter dininishes the accuracy of the solution and cuts the time step required for stahility below that given by the Courant number. These codes are not practical for studying wave propagation for large distances from the source and for long (solution) times. Since the solution must be computed in a finite domain, the radiation and regularity conditions restrict the domain of intercst and at a time at which the solution remains valid. These conditions require that the solution be bounded $a !$ intinity and that no waves propagate from infinity into the solution region. Presently, the conditions are replaced by free boundarics at large distances from the source. Hence the solution remains valid until waves have time to propagate hack into the so'ution comain. Large-solution domains requir: that these boundaries be placed a large distances from the source.

To eliminate waves propagating back from arificial boundaries, non-reflecting boundary conditions can be placed outside the domain of interest. However, at present, only li.ilited success has been obtained with these a bsorbing-boundary conditions. Another restriction on the length of time the solution may be successfully computed is the stability criterion. The usual stability criterion used in large finite-difference codes allows exponential growth of the solution with time. Gussafsson (1969) has shown that the usual stability definition is not sufficient for long-time solutions of hyperbolic differential equations. A discussion of the stability of hyperbolic differential equations is not considered further in this report. I mention it only to point out the difficulty of obtaining long-time solutions to the governing equations.

In seismic monitoring research, large finitc-difference and finite-element codes are only practical for calculations in the near-source region and for short times. They may be used for studying effects of material propertics in the immediate vicinity of the source (î they can be modeled) and for st udying the effects of materiat boundaries on the source function. Finite-difference and finite-element codes calculations may be used to provide boundary conditions (or representations of nonlinear region of nuclear explosive and earthquake sources) for integral-transform methods capable of computing the response at large distances from point sources or computing representations of these [Cherry et al., 1975].

The characteristic approach is probably the most accurate of the available techniques. It gives a geometric interpretation of hyperbolic partial differential equations. This method is based on propagating singular surfaces called bicharacteristics in the solution of the differential equations. In iurn, a set of equations, better known as compatibility equations, is derived from the basic conservation and constitutive equations and is integrated numerically along curves (bicharacteristics) that coincide with the generated waves [Courant and Hilbert, 1962; Ziv, 1969, 1975a, 1975b, 1976; Clifton, 1967; Recker. 1970; Karpp and Chou, 1972]. At present the method of characteristics requires detailed analysis for coding, particularly when shocks are involved, and is not generally used unless accurate solutions are required. For linear problems, tharacteristics of the same family do not intersect and a shock-free solution results. Under these circumstances, the programming complications are reduced and the method can thus be fruitfully applied to linear elastodynamic problems. 
Iraditionally, seismologists are unfamiliar with the method of characteristics as a solution technique to hyperbolic equations. Howeser, because of its intrinsic geometric property, this technique is the most appropriate for understanding wave-interaction problems. Adıantages and disadvantages of the method of characlerintics over finite-diffefence'techniques were discussed by Hoskin (1964) and are presented in Table 2, which is basically adapted from karpy and Chou i 1972). In a later section of this paper. I present applications of the computational methods discussed above.

\section{THE INVERSE PROBLEM}

The problem under consideration is that of estimating state variables and parameters in noisy linear and nonlinear systems. Two methods are available for the inversion of seismological data:

(I) Direct inversion of data the solution of the problem is obtained by a direct (mathemafical) inversion of data.

(2) Trial-and-error methods - find a set of system parameters for which theoretically caiculated properties of waves agree with observations.

\subsection{DIRECT-INVERSION METHOD}

For discussion purposes, I assume that both the geophysical data and the solution to be found can be described by a finite number of parameters. The results are easily generalized for the case in which data or solution or both are represented by continuous functions. The inverse method requires the following:

(1) Choose a model and develop Eq. (1).

(2) Develop a parameter estimation theory.

(3) Assume a set of initial model parameters that the inverse method initially uses to seck a fit betweer the observed and theoretically computed data in the region of the initial guess.

Figure 4 depicts the flow diagram for this process.

The a priori data summary contains empirical relationships, structural models, limitations, and any other relevant information about the physics of the problem. These data represent our general knowledge on seismology, gcophysics, and the seismic system considered applicable to the problem under investigation.

TABLE 2. Comparisons between finite-difference codes or between finite-element codes and between methods of characteristic codes.

\begin{tabular}{|c|c|c|}
\hline Property & Finite-diftertnce or finite-element code & Characleristir code \\
\hline 1. Logic & Simple & Complicated \\
\hline $\begin{array}{l}\text { 2. Increast in diffculty due to multiple } \\
\text { materials and variety of problems }\end{array}$ & Litile & Great" \\
\hline $\begin{array}{l}\text { 3. Treatment of discontinuities and their } \\
\text { interactions }\end{array}$ & Smeared; uncertainty in posillon & Treated explicitly \\
\hline 4. Profiles & Noisy & Smooth between discontinulties \\
\hline 5. Details of solution & Poorly defined & Good \\
\hline 6. Time step & $\begin{array}{l}\text { Usually determined by stability of } \\
\text { smallest mesh }\end{array}$ & Variable in space and time \\
\hline 7. Number of meshes within material & $\begin{array}{l}\text { Usually fixed; needs a minimum to let } \\
\text { shocks form propesly }\end{array}$ & $\begin{array}{l}\text { Varied during a problem to give detall } \\
\text { where needed }\end{array}$ \\
\hline B. Lise of computer & $\begin{array}{l}\text { Poor-many meshes requied for } \\
\text { accuracy }\end{array}$ & Optimum \\
\hline
\end{tabular}

\footnotetext{
"For general constitutive models the characteristic approach cannot be used bectuse no theory is avilable for determining compatibility
} retations across discontinuities. Only a shock theory for conservation laws is developed. 
The observaiional data necd little comment. These are the raw observations from the seismogram corrected for noise and instrument effects. They may, however, be divided into body. Rayleigh, and love waves and into spheroidal and torsional-free oscillations depending on the application. Burridge (I976) presents a detailed description of different seismic phases.

With the data input above, the cstimation procedıre begins with the representation of the forward problem by a fin'te number of parameters, i.e., development of the estimator Eq. (1). For example, see [Hudson, 1969a, 1969b: Langston and Helmherger, 1975; Johnson. 1974; Buland. 1976] for details. Herc l assume n-data parameters $u_{i}, m$ solution paramcters $\alpha_{j}$, and $n$ known functions $F_{i}\left(\alpha_{j}, j=1, \ldots m\right)$, which give the predicted data parameters for any admissible set of $\alpha_{\mathrm{j}}$. I call any admissible set of $\alpha_{\mathrm{j}}$ a "model" and define the residuals $\mathrm{e}_{\mathrm{j}}$ for any model to be the observed data minus the theoretical prediction:

$$
c_{i}=u_{i}-F_{i}\left(\alpha_{j}\right), \quad i=1,2, \ldots, n
$$

The inverse solution now sccks to find all those models sucb that the error (residual) in some norm is acceptable and any a priori constraints are statisfied. This defines a parameter estimation theory. In this problem, the solution parameters $\alpha_{\mathrm{j}}$ are either (1) the hypocentral cnordinates and origin time of the event; (2) the layer densities, thicknesses, $P$ and $S$ wave velocities, and attenuation parameters; (3) the energetic parameters of the source; or (4) combinations of the above.

The formulation of Eq. (28) and the setting of limits on parameters complete the seismology of the problem. At this stage, the problem bicomes a mathematical one for the solution of Eqs. (28) subject to constraints. Discussions of modern general parameter estimation theory may be found in Bard (1974). The principle technique is constraint optimization. As shown in Fig. 4, two paths may be taken in the solution process, linear or nonlinear estimation. Stump and Johnson (1977) used the general Green's function in:- gral representation to formulate the following linear representation:

$$
u_{k}\left(x^{\prime}, t^{\prime}\right)=G_{k i, j}\left(x^{\prime}, t^{\prime} ; 0, o\right) * M_{i j}\left(o, t^{\prime}\right)
$$

or

$$
\overline{\mathbf{u}}_{\mathrm{k}}\left(\mathrm{x}^{\prime}, \mathbb{1}\right)=\overline{\mathrm{G}}_{\mathrm{ki}, \mathrm{j}}\left(\mathrm{x}^{\prime}, f ; 0,0\right) \bar{M}_{\mathrm{ij}}(\mathbf{o}, 1)
$$

for determining the equivalent source representation in terms of the moment tensor $\mathbf{M}$. Where $x^{\prime}, t^{\prime}$ are the receiver coordinates and the time relative to the receiver-coordinate system, respectively, $G$ is the Green's function, [Johmson, 1974], $\mathrm{G}_{\mathrm{ki}, \mathrm{j}}$ are the spatial gradients of the Green's function, $u_{k}$ are the components of the displacement vector and $f$ is the frequency, and (*) represents a convolution. The idea of the formulation [Eqs. (29) and (30)] is to use the observed values of ground displacen.ent $u_{k}\left(x^{\prime}, t^{\prime}\right)$ to infer the properties of the source as characterized by $\mathrm{M}_{\mathrm{ij}}\left(0, \mathrm{t}^{\prime}\right)$. The physics of seismic sources must be well understood in terms of moment tensors for this approach to be useful for seismic discriminations. Under this formulation one proceeds directly to the box marked inversion in Fig. 4.

Almost all estimators for determining hypocentral coordinates and earth models use the general nonlinear formulation. Examination of the parameter space (Fig. 4) requires development of some procedure for finding a minimum for the residual $\mathrm{e}_{\mathrm{i}}$. By quasi-linearization, the nonlinear estimator may be cast in the linear form

$$
\Delta \mathbf{u}=\mathbf{A} \Delta \mathbf{\alpha}
$$

about some starting solution $\alpha^{\circ}\left[\right.$ Jackson, 1972], where $\Delta u_{i}=u_{j} \cdot F_{i}\left(\alpha_{j}^{\circ}\right)$, the residual for the starting model, and $A_{i j}=\left[\partial F_{i} / \partial \alpha_{j}\right] \alpha_{j}$, the matrix of partial derivatives. 


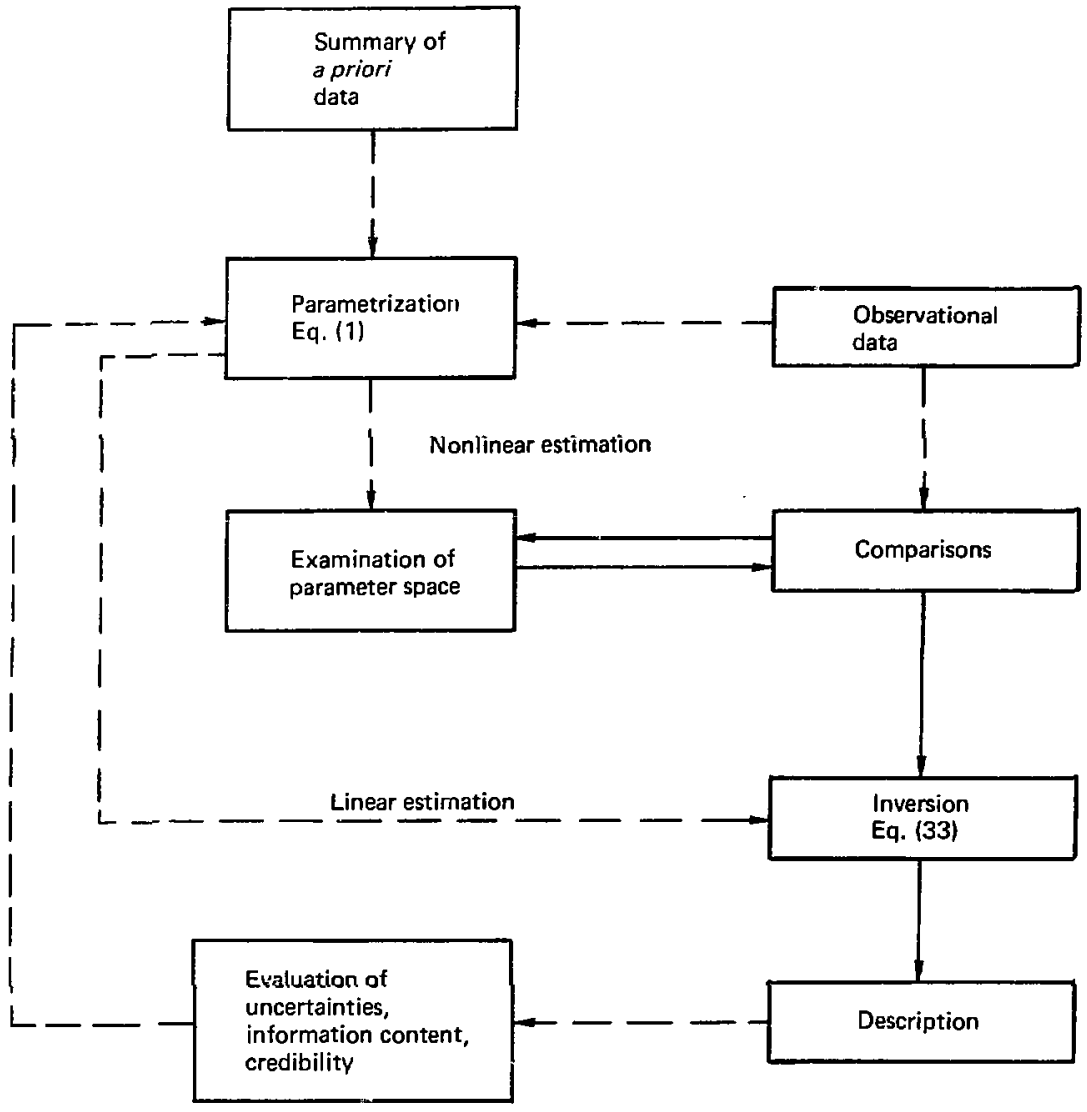

FIG. 4. Direct method of data inversion. 
Eqs. (31) now define a linear system of $n$ simultaneous equations to solve for $m$ unknown parameter corrections $\Delta \alpha_{i}$. The solution of the problem requires the computation of the partial derivatives or variational parameters $\partial F_{i} / \partial \alpha_{j}$ as well as the functional values $F_{i}\left(\alpha_{j}\right)$.

The inverse problem one must solve is to determine the "best" estimate of the model parameters with respect to some measure of the error. For example, the least squares formulation minimizes the cxpression

$$
\sum_{i}^{N}\left[u_{i}\left(\alpha_{j}\right)-F_{i}\left(\alpha_{j}^{\circ}\right)\right]^{2}
$$

over all choices of the unknown parameters. Claerbout and Muir (1973) discuss the merits of absolute value error norms over least squares and of ignoring erratic data points. Generally no particular estimation technique is uniformly valid for all inverse problems. Details of specific estimators in wide use (such as least squares, maximum likelihood, Bayesian and others) are thoroughly discussed in the book by Bard [1974]. These discussions include methods, computations, and interpretations of estimates.

The choice of the model and the selection of initial estimates of the unknown parameters within the model are basically a priori selections. The geologic and geophysical knowledge of the area being studied influence the selection of initial parameters.

The next step in analysis is the direct inversion of either Eqs. (29) and (30) or of Eqs. (31) to determine the moment tensor $M_{i j}$ or the model parameters $\Delta \alpha$. In discussing the details of the inverse method it is convenient to write Eq. (29) and (30) or Eqs. (31) in matrix form:

$$
\mathbf{U}=\mathbf{A P} \text {, }
$$

where $\mathbf{U}$ consists of sampled values of the observations and is a vector of dimension $\mathrm{n}$. The matrix $\mathbf{A}$ is composed of the Green's functions Eqs. (29) and (30) or the variational coefficients Eqs. (3l) and is an $n \times m$ matrix. The vector $P$ is made up of either the components $M_{11}, M_{12}, M_{13}, M_{22}, M_{23}, M_{33}$, Eqs. (29) and (30) or the components $\Delta \alpha_{k}, k=1,2, \ldots, m$, Eqs. (31). The vector $\mathbf{P}$ contains $m$ components. The problem is undetermined, exact, or overdetermined depending on whether there are less than $m$, exactly $m$, or greater than $m$ observations, respectively. The determination of parameters $P_{k}, k=1,2, \ldots$, m may be approached by operating on both sides of Eqs. (33) with an $n \times m$ operator $H$ and defining the model [Jackson, 1972]:

$$
\hat{\mathbf{P}} \equiv \mathbf{H A P}=\mathbf{H} \mathbf{U} \text {. }
$$

The operator $\mathbf{H}$ provides information on both the uniqueness of the solution and the resolution of the model. Back us and Gilbert (1968) pointed out that for under-determined systems, the product matrix $\mathbf{H} A$ has a physical meaning related to the uniqueness of the solution. The matrix $\mathbf{H A}=\mathbf{R}$ maps the entire set of solutions $\mathbf{P}$ into a single vector $\hat{\mathbf{P}}$. Any element $\hat{\mathbf{P}}_{\mathrm{k}}$ may be interpreted as the result of convo!ving the $k^{\text {kh }}$ row of $\mathbf{R}$ with any vector satisfying Eqs. (33). If $\mathbf{R}$ is an identity matrix, the solution $\hat{\mathbf{P}}$ is unique and each element is perfectly resolved. The degree to which $\mathbf{R}$ approximates the identity matrix is a measure of the resolution obtainable from the data. The rows of $\mathbf{R}$ are called resolving kernels.

In a similar way, Wiggins (1972) showed that for over-determined systems the product $\mathrm{S} \equiv \mathrm{AH}$ is a measure of the independence of the data. The matrix $S$ is referred to as the information-density matrix and tells how well the model fits the data since $\mathbf{A} P=\mathbf{U}$ if $\mathbf{A} \mathbf{H}=I_{n}$, the $n \times n$ identity matrix.

For the systems discussed above, the matrix A can be decomposed [Lanczos, 1961]:

$$
A=W \wedge v^{T}
$$

where $\mathbf{W}$ is an $n \times p$ matrix whose columns are the eigenvectors associated with the nonzero eigenvalues of $\mathbf{A A}^{\mathrm{T}}$, $\mathbf{V}$ is the $\mathbf{m} \times \mathbf{p}$ matrix whose columns consist of similar eigenvectors for $\boldsymbol{A}^{\mathrm{T}} \mathbf{A}$, and $\boldsymbol{A}$ is a diagonal matrix of the 
positive square roots of the $\mathbf{p}$ nonzero eigenvalues of $\mathbf{A}^{\mathbf{T}} \mathbf{A}$. With this notation, the generalized inverse $\mathbf{H}$ becomes

$$
H=V \Lambda^{T} W^{T} \text {. }
$$

The inverse $\boldsymbol{H}$ yields no information on eigenvectors associated with zero eigenvalues. The eigenvalues of $A^{T} A$ indicate whether the problem allows a unicue solution for $P$. Since numerous discussions of the generalized inverses are in the literature [Lanczos, 1961; Wiggins, 1972; Jackson, 1972] 1 will not comment further on this aspect of the problem.

Discussions on the inversion of Eqs. (29) and (30) or Eqs. (31) for the determination of source parameters and the earth's structure can be found in the works of Budyanskit et al. (1975), Crosson (1976a, 1976b), Wiggins (1972), Buland (1976), and Stump and Johnson (1977). Jordan and Franklin (1971), Gilbert (1971b), Wiggins (1972), and Jackson (1972) give methods for finding the number of independent pieces of information present in a set of observations. This number is essentially determined by the ratio of allowable standard deviation in model parameters to the standard deviation of observations. These authors also present a discussion on the sensitivity of the results of the inverse procedure to the uncertainties in the data. This is usually characterized by the condition number of the problem (approximated as the ratio of the largest to smallest eigenvalue). Detailed discussions on uncertainty and information content are not presented in this report as they are readily found in the above works and in Chapter 10 of Bard (1974).

\subsection{TRIAL-AND-ERROR METHOD}

Figure 5 shniws the general scheme for this method. Many of the operations are the same as in the direct-inversion method and are not repeated here. The examination of the parameter space in this case is carried out on the basis of the mathematical formulation of the problem: finding the space of unknown parameters in the region of the minimum of the residual, $e_{j} \equiv u_{i}-F_{i}\left(\alpha_{j}\right)$, the region where the measure of the disagreement between calculated and observational data is below the allowable level. In the trial-and-error method, the conventional techniques for finding the minimum are Monte Carlo, random search, and steepest descent techniques [Asbel et al., 1966; Valyus, 1972; Jackson, 1973; Balk, 1977].

Examination of the parameter space essentially consists of theoretically calculating the response functional [Eq. (1)] for an assumed set of unknown parameters and comparing with observations. If the comparisons are sufficiently good, a description is assumed. Detailed discussions on this technique are in the above references.

The trial-and-error method is greatly used by seismologists for determining the earth's structural model and source-time functions [Anderson, 1975; Richards, 1975; Langston and Helmberger, 1975; McMechan, 1978]. Valyus (1972) and Jackson (1973) give clear discussions on techniques for examining uniqueness and regions of uncertainties of solutions by tritl-and-error methods. For completeness, 1 present the discussion by Valyus (1972) for studying the minimum region of a multivariate function (hedgehog method).

The trial-and-error inethod as presented by Valyus (1972) consists of the following procedure. The nodes of the coordinate grid in the space of unknown parameters a re examined by the Monte Carlo method. At each node the residual, $e_{i}(j=1, n)$ for all $j$, is calculated and checked to determine if it belongs to the desi-ed minimum region. After a node belonging to this region is found, the adjacent node residuals are checked. It is detertitined which of these nodes belong to the minimum region. Corresponding aojacent nodes are then considered for each of these nodes. The procedure continues until all nodes in the minimum region have been investigated. That is, the nodes of the coordinate grid within the minimum region are examined as long as it is possible to move from one node to the next. Then a new part of the parameter space is searched by the Monte Carlo method to determine whether other minimums exist (nonuniqueness). Each node is only examined once. In this way both the uncertainties in the estimated parameters and uniqueness of solutions are obtained simultaneously. 


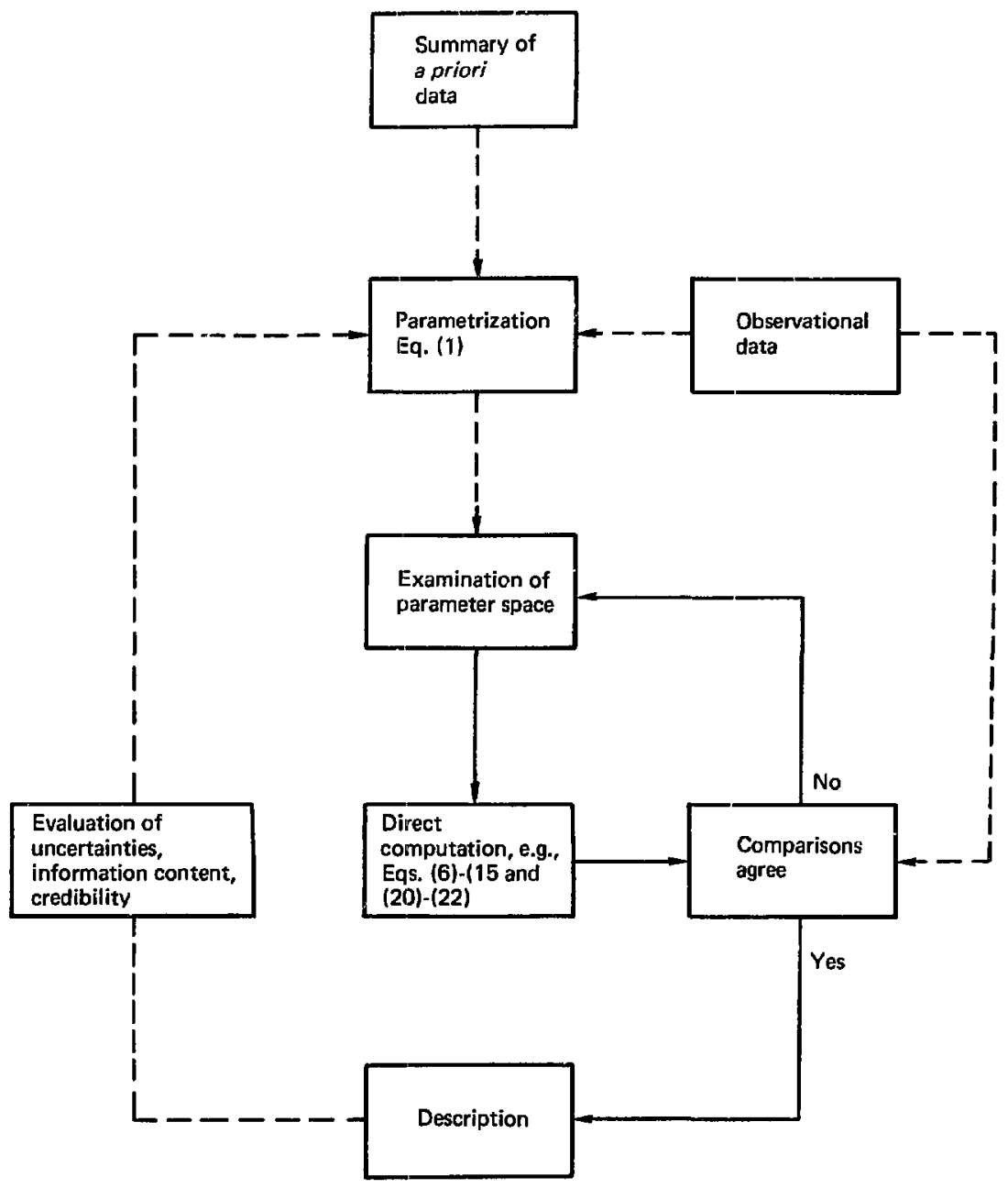

FIG. 5. Trial-and-error method of data inversion. 
This technique is illustrated in Fig. 6 for the two-dimensional case (two unknown parameters). The intersections of the straight lines are the nodes. In this example two minimums called $A$ and $B$ clearly demonstrate nonuniqueness. Point 1 is found by the Monte Carlo method, and point 2 is the nearest node. It belongs to A. Table 3 compares this teclanique with the direct-inversion method.

I have discussed two general methods for determining seismic source parameters and the earth's structure. The key elements in the solution are the representation of the estimator by a finite number of parameters, the cataloging of a data summary, and the network for obtaining the observational data. In the next section 1 list computer codes that are direstly applicable to solutions of the inverse problem. For definiteness, a computer code is literally a program of instructions that when executed on a computer yields a collection of numbers. In practice, it is the embodiment of a particular formulation of a provitem and a given method of solution [Chin, personal communication, 197/3]. I will now briefly discuss the availability of these codes and the additional developm, nt needed to consplete the computational effort.

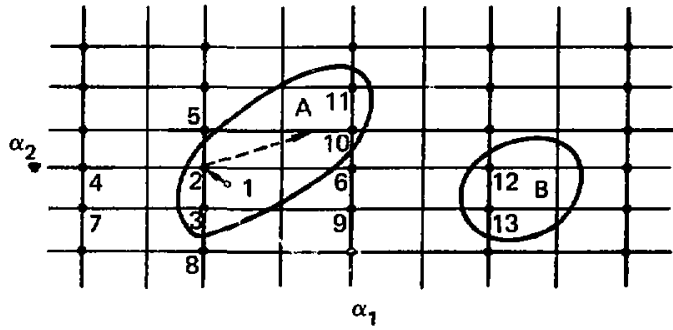

FIG. 6. Examination of parameter space by the hedgehog method (after Valyus, 1972).

TABLE 3. Comparisons of direct inversion and trial-and-error methods of data inversinn.

Direct inversion method

Advantages

Disadvantages

Trlal-and-error method Advantages

Disadvantages
Minimum of function easily obtained, hence smaller amount of computation time

In nonlinear formulation, poorly equipped for describing uniqueness of solution obtained Matrix inversion for solution

Equipped to span entire parameter space for solutions

Joint analyses of largest amount of difrerent data-any date for whleh forward problem ean be formulated

No matrix inversion

Large number of evalunilons for solution to forwand problem 


\section{COMPUTER CODES FOR SEISMIC-MONITORING RESEARCH}

The computational procedure necessary to carry out the analysis of seismograms may be represented by thiee major computational areas: (1) network analysis, (2) the forward-wave propagation problem, and (3) the inversion problem.

\subsection{NETWORK CODES}

Networks of seismic stations provide the observational data used to study source mechanisms and develop the data summary. With the renewed interest in a comprehensive test ban treaty, regional networks will be necessary for gathering seismic data when event 5 are 100 small to be detected teleseismically. The number of stations within these regional networks may be limited to a few. Hence, the regional network's capability of not only detecting but also of locating events must be assessed. Flinn (1965), Evernden (1969) and Buland (1976) have shown that location capability depends on the azimuthal distribution of individual stations within the network. Therefore, one must develop or use existing computational codes with a limited number of stations to evaluate the capability of detecting and Jocaking seismic events.

Evernden (1969) has provided a system analysis for the evaluation of seismic networks. The purpose of this evaluation is to provide information on the credibility of a network. Figure 7 depicts this procedure, which essentially consists of solving a forward problem based un a data summary for evaluating detection capability and solving an inverse problem for evaluating the network's location capability.

Input data follow:

(1) Maximum number of stat:ons used in the network.

(2) Station locations and noise level.

(3) Noise and signal variances expressed in magnitude units.

(4) Magnitude corrections as a function of distance for different phases.

(5) A sufficient number of test epicenters to allow valid contouring.

(6) A set of travel time tables with standard deviations in travel times for observable phases. As shown in Fig. 7, the network analysis code combines seven subroutines for computational purposes.

Lawrence Livermore Laboratory (LLL) presently uses an existing code NETWORTH for evaluating detection capability and for designing regional networks. This code provides one of the functions of the general code outlined in Fig. 7. Given a set of stations and a description of travel time :ables and probabilities of detection, this code computes the minimum magnitude of an event that can be detected from a given network of stations. Four phases are used for detection, $L_{8}, P_{B}, P$, and $P_{n}$. The capability of this code for evaluating the uncertainties in locating the hypocenters is in error [Hannon, personal communications, 1978]. Thus added development is necessary, as depicied in Fig. 7. Essentially LLL needs to develop Part B of Fig. 7.

For locating hypocenters, the code HYPO7! [Lee and Lahr, 1975] is available. This code uses a modified form of Geiger's (1910) method, which includes depth of Socus. Briefly the method is as follows: the observed arriva time of a seismic phase at a seismic station is defined by

$$
t_{i}=f_{i}\left(t_{0}, \Delta_{i}, h\right) \quad i=1,2, \ldots, N
$$

where $t_{i}$ is the observed arrival time at station $i_{\text {. }} t_{i}$ is a nonlines function of the origin time $t_{0}$, the epicenterstation distances $\Delta_{j}$, and depth of focus $h . \Delta_{i}$ is a nonlinear function of the epicenter colatitude $\phi$ and longitude $\lambda$. $N$ is the number of observations used in the location procedure. Equation (37) is expanded in a Taylor series about some approximate values of the parameters and linearized by retaining only the first-order terms. The station residuals resulting from the hypocenter approximation are

$$
e_{i}=t_{i}^{*}-\frac{\partial f_{i}^{*}}{\partial t_{0}} \delta t_{0}+\frac{\partial f_{i}^{*}}{\partial \Delta_{j}} \delta\left(\Delta_{j}\right)+\frac{\partial f_{i}^{*}}{\partial h} \delta h \quad i=1,2, \ldots, N,
$$

where $f_{f}\left(L_{0}, \Delta j, h_{0}\right)$ are the estimated arrival times calculated from the approximate location and $t_{i}^{\prime \prime} \equiv t_{i}-f_{i}\left(l_{0}\right.$, $\left.\Delta_{i}, h_{0}\right)$. Corrections to the starting solution are found by minimizing the residuals $e_{i}$ in the least squares sense. 


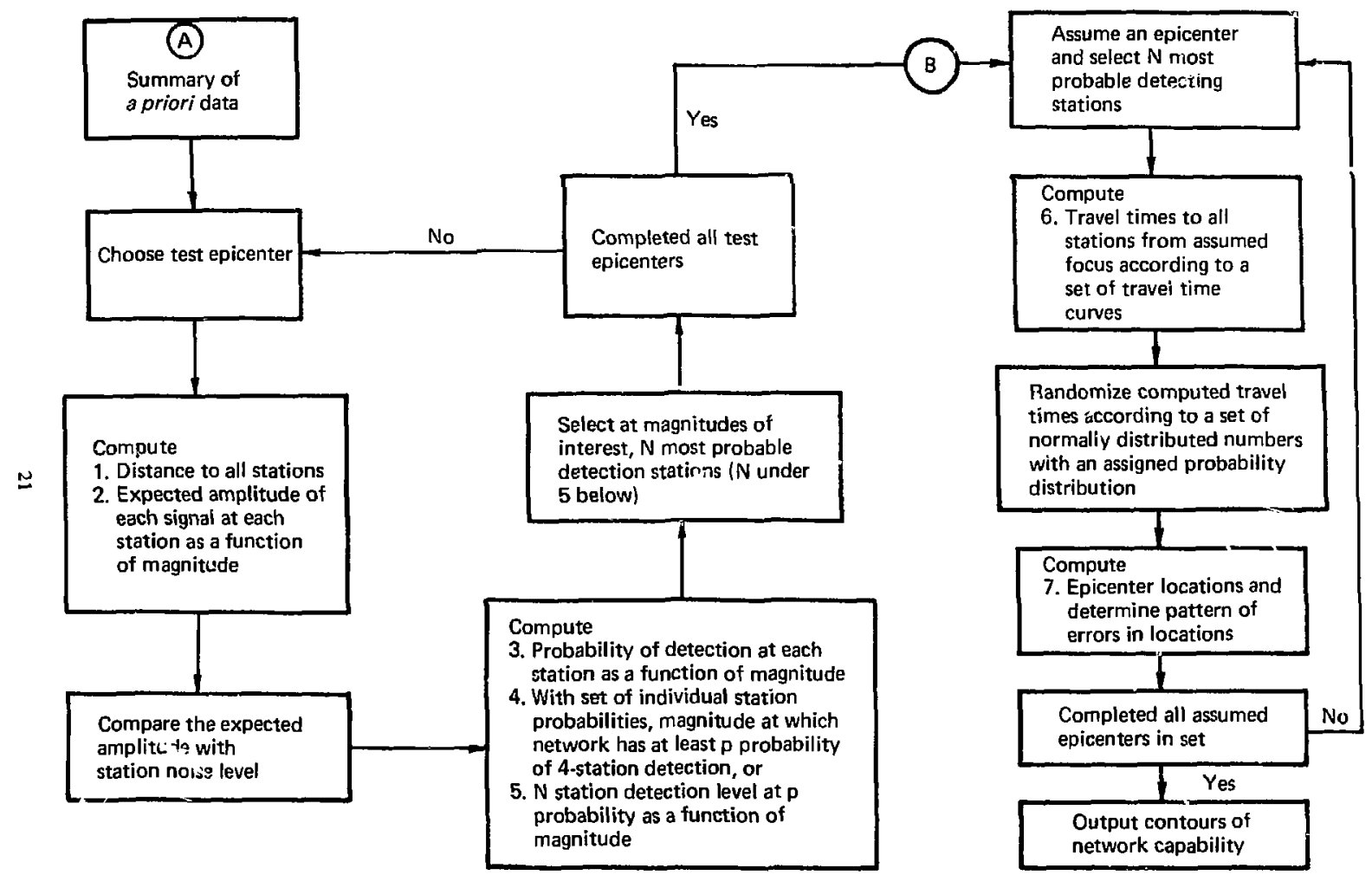

FIG. 7. Network analysis flow diagram to evaluate capability of detecting and locating seismic events. The probability, p, is an input parameter. 
Corrections to the starting solution require matrix inversion. The old values are updated and the procedure continues until the process converges. It is well known that numerical instability occurs in the matrix inversion procedure F.qs. (31) if the Jacobian is ill-conditioncd. To remove this instability, HYPO7I uses a stcpwise multiple regression, varying only those parameters that have undergone a s:gnificant change at each step. It happens, however, that this can lead to convergence to the wrong solution; i.e., some of the parameters may never change from their starting values. Hence for HYPO7/ to be useful for a general seismic monitoring system, added development on this code is required. e.g.. the use of singular value decomposition for illconditiored matrices. Buland (1976) gives a detailed discussion of the mechanics of locating seismic sources.

Because of the volumes of data that must be processed for any monitoring program, techniques must be developed for automatic recording and processing of data. At LLL, DS ${ }^{2}$, a minicomputer system to automatically record four stations and output digital information, is being developed [Denny, personal communication, 1978]. Effort in this area must continue to complete the codes required for seismic networks.

\subsection{WAVE-PROPAGATION CODES ;}

The forward solution (wave propagation) provides the theoretical basis for all inversions considered in this report. Hence any general seismic system that one develops must contain codes to study wave propagation in any geologic environment. The codes are listed below.

\section{F. iite-Difference Codes}

Two finite-differencc codes (SOC and TENSOR) were developed at LLL to study wave propagation from explosive sources in geologic materials. These codes solve Eqs. (6) through (15) and (20) through (22). The physics of these codes is described by Schatz (1973) and Burton and Schatz (1974). The SOC code solves the one-dimensional analog of Eqs. (6) through (15) and (20) through (22) in planar, cylindrical, and spherical geometries. TENSOR is the two-dimensional counterpart of the SCC code. It was developed to stuoy cylindrically symmetric and plane-strain problems where two spatial variables are required. In these codes, energy is usually deposited at an inner boundary and boundaries away from the sourcc are usually assumed to be free surfaces. Motion is initiated by simulating a nuclear explosion or its approximations, chenical high explosives, pressure or velocity at a boundary. and velocity or precompression in a region. In the simulated nuclear explosion the innermost region in the proilem is specified as an iron gas with the appropriate volume and mass of the nuclear device [Schatz, 1973, 1974]. The st:enical explosive allows energy to be dcposited over a finite time as compared with the nuclear explosion, which is assumed to deposit its energy instantaneously. The other methods for initiating motion are prescr:'hed pressure- or velocity-time functions.

\section{Finite-Element Codes}

Frazier and Petersen (1974) developed a three-dimensional finite-element code to study dynamic faulting that may be available. This code essentially uses the elastic-rebound theory [Archuleta and Frazier. 1978]. The earthquake is represented as a propagating stress relaxation over a finite fault within a half-space. To implement the model, Frazier and Petersen specify the hypocenter, the geometry of the fault plane, the rupture velocity, the initial stress in the medium, and the coefficient of sliding friction. This type of code, which uses either the finite-difference or finite-element formulation, is necessary to study the physics invoived during faulting, i.e., in regions of large deformation.

Important elements lacking in the finite-difference and finite-element eodes are rational sehemes for trcating shear-volume interactions, rate dependent effects, multiple phases, and thermal effects. The lack of these effects limits the ability of the codes to give a complete description of the problem. I would like to emphasize that the inclusion of these phenomena may change the mathematical structure of the resultant field equations. This, in turn, necessitates a reexamination of the solution technique. Presently it is not known how to correctly model these effects.

I would like to remark that discretization of the differential equations by finite-tlement or finitedifference methods introduces numerical dispersion, whose effect is to convert the wave-propagation problem 
in a nondis sersive medium to that with dispersion. Manifestations of dispersive effects on propagation of singularities are amply discussed in Brillouin (1960). Using techniques of dispersive wave theory. Hedstrom (1968), Chin (1975) and Chin and Hedistrom (1976, 1978) obtained crror bounds accounting for the sffect of numerical dispersion on propagating sirgularities.

\section{Integral-Transform Codes}

Presently LLL has access to a generalized-ray tracing sode (Cagniard-de Hoop). a reflectivity code. and two codes using mode summation. The application of Laplace, Fourier, or Hankel or all transforms to the equations of linear elasticity [linearized form of Eqs. (20) through (22)] in laterally homogeneous media reduce these equations to systems of ordinary equations in the transformed variables. The evaluation of the synthetic seismograms is now divided into two parts: (1) the solution of the ordinary differential equations for the transformed variables, with appropriate regularity and boundary conditions, and (2) the evaluation of the inverse transforms. The integral transforms are essentially represented by two integrals, one with respect to frequency and the other with respect to the horizontal-wave number or equivalent horizontal-wave slowness. If the wavenumber integral is evaluated first the method is called the spectral method, whereas evaluation of the frequency integral first results in the slowness method. These methods are further divided, depending on whether the wave-slowness integral is evaluatird along the real axis or distorted into the complex plane [Chapman, 1978].

The generalized ray method [Cagniard-de Hoop] as discussed by Chapman (1978) is a special case of the slowness method. In the generalized-ray method, the integration path of the real-wave-slowness integral is distoried into the complex plane and the inverse-frequency transfo: $m$ is applied first.

The reflectivity methor [Fuchs and Muiller. 1971] results when the variable of integration is taken as the iay angle rather than as the siruwness, and the integration range is restricted to real angles. The transformed response is generally found for a plane-layered model using the Haskell matrix method [Haskell, 1ȳ53].

The codes using mode summation [Schwab and Knopoff, 1972] are being developed by Nakanishi (personal conımunication, 1978). Nakanishi intends these codes for studying the effects $c$ f parameters (i.e., velocity structure, layering, etc.), on pure scismic signals. These codes may also be used for strong-motion studies in the near field and for generating dominant seismic phases seen on regional seismograms.

Other relevant codes on hand are SIEP and INST. SIEP is an integral transform to study the propagation of certain phascs through teleseismic distances in the frequency doinain. Instrumental effects on the seismic waves can be corrected by convolvi:g the output of SIEP with INST. INST is a British code that computes instrump?t response for several excitations [ $T u l l$, personal communication, 1978]. In comparing synthetic seismogi ams with ubservational data, it is necessary to either convolve the instrument response with the synthetic or deconvolve it from the data.

Another available integra]-transform code:s tr.e "Big E" as called by seismologists at LLL [Seismic Group, K-Division]. The mathematics of this codt is developed in two papers by Hudson (1969a, 1969b). Hudson develops this algorithm to calculate pulse shapes of body and surface waves at teleseismic distances in a layered elastic half-space (waves recorded at epicentral distances between 30 and $\left(00^{\circ}\right.$ ) from both explosive and shallow earthquake sources. Cylindrical coordinates are employed. The code uses Haskell's matrix method to account for layering at the source and receiver. Attenuation due to linear anelasticity is allowed by an empirical factor, and the sphericity of the earth is accounted for by a geometrical spreading factor. This code solves the problem in the frequency domain and uses geometric-ray theory for propagation of body waves through the mantle. Added development is necessary if this code is to be used to compute synthetic seismograms for body waves at regional distances.

Integral-transform codes use :quivalent elastic-source representation for the generation of seismic waves whereas the finite-dirfcrence and finitı-element techniques directly incorporate the source physics in the problem formulation. Hence to understand how the physics of the source affects the waves at large distances, the solution of the close-in region must be represented as an equi ." lent elastic source [Cherry et al., 1974]. Then integral-transform methods can be used to obtain the responsc a: listances where seismograms are recorded. 


\section{Method of Characteristics}

The development of a code using the method of characteristics is necessary to study the generation of seismic phases, particularly the generation of the Rayleigh wave and regional phases, $\mathrm{L}_{\mathbf{g}}, \mathbf{P}_{\mathrm{g}}$, used in seismic-discrimination studies. Ziv (1975b) developed a method-of-characteristics code to stidy the transicnt response of an elastic half-space to an embedded cylindrical load. This code is available from the U.S. Air Force Office of Scientific Research. Other relevant available codes may also be used [e.g., Clifton, 1967; Recker, 1970].

\subsection{SEISMIC-INVERSION ROUTINES}

Inversion studies in seismic-monitoring research are basically concerned with hypocenter locations, the resolution of the earth's structure, and determination of the source's parameters and its time function. HYPO7I, an inversion code, contains all the routines depicted in Fig. 4 for locating hypocenters. For determining the earth's structure or the seismic-source function, wave-propagation codes replace the estimator [Eq. (37)] in HYPO71-providing a necessary system of inversion codes. However, HYPO71 uses the directinversion method, and I suggest the need for a trial-and-error inversion capability as it is applicable to any problem in which the forward problem can be formulatec. This requires the development of the algorithm for the examinarion of the parameter space, discussed in Section 3.2.

In this category LLL has another inversion routine called SEP [Tull, personal communication, 1978]. This code uses homomorphic deconvolution to look at signals separated in time. The idea is to take the $Z$-transform of a sequence of sampled data $x(n)$ that has been convolved with another discrete sequence. As the Z-transform of a convolution is the product of the Z-transform of the individual signals, one obtains, after taking the logarithm of the Z-transform, a sum of the logarithm of the two discrete signals. The inverse Z-transform $\hat{x}(z)$ gives the input to a linear system. $\hat{x}(n)$ has been termed complex cepstrum. Then by removing values of the complex cepstrum near the origin, a slowly varying component of both phase and log amplitude spectra may be removed [Ulrych, 1971; Stoffa et al., 1974].

Inversion studies require matrix-inversion routines. As pointed out earlier, the least squares iterative scheme becomes numerically unstable for ill-conditioned matrices. Hence one must use some of the more modern techniques made available by the Numerical Mathematics froup at LLL to handle these cases.

In the next section $I$ outline a general system for the analysis of seismograms. Because the initial signal processing requires a number of operations, special routines are needed. For completeness I mention that Robinson (1966) published a collection of FORTRAN programs for filtering and spectral analysis of a singlechannel time series.

\section{ANALYSIS OF OBSERVATIONAL SEISMIC DATA}

The system for analysis of observational data as applied here is adapted from the methodology developed by Keilis-Borok (1972) in a paper on seismology and logic. It has four major structural elements: analysis of a single seismogram, analysis of source parameters, basic rules, and seismological conclisions (Fig, 8). For completeness, this section contains a brief discussion of a general analysis code.

\subsection{ANALYSIS OF A SINGLE SEISMOGRAM}

The initial operation in seismic-data analysis is to detect signals in a noise background (microseisms or other signals). This operation, which may require filtering of the seismogram, can be done from a visual recognition of seismic phases. The next operation is the measurement of the parameters of the individuat signals or groups of signals: arrival time, maximum amplitude, apparent period, polarization, and duration of oscillation. The preliminary identification of a signal in terms of a known wave type (phase) is based on the 


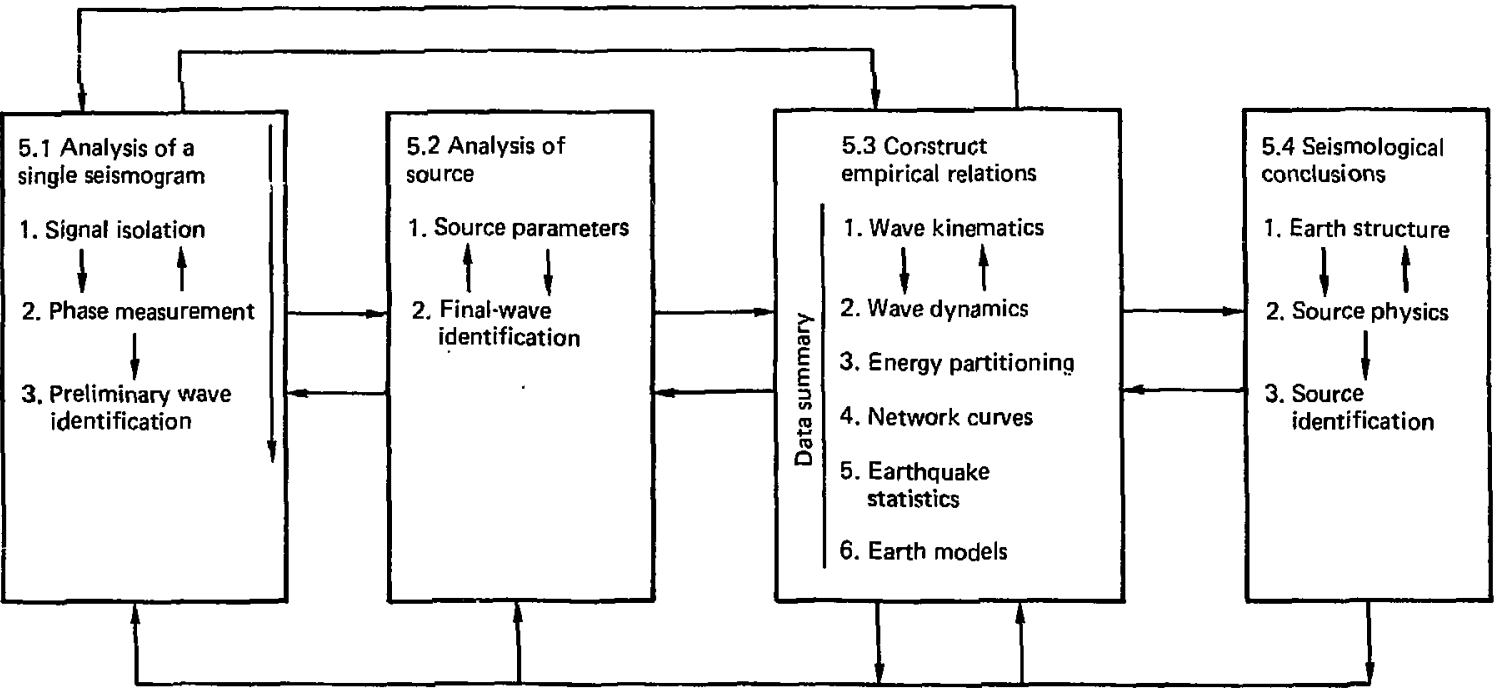

FIG. 8. System to analyze and interpret seismograms [adapted from V. I. Keilis-Borok, "Seismology and Logic," in Computational Seismology, V. I. Keilis-Borok, Ed. (transjated from Russian by Consultants Bureau, New York, 1972)], 
measurements made above (arrival time) and on an intuitive or visual recognition of waveform. Seismic spectra may also be obtaincd here for later use, particularly for identifying source mechanisms. (e.g., explosion or earthquake).

\subsection{ANALYS'S OF SOURCE}

Source parameters (epicenter, focal depth, mechanism, energy or magnitude, and sometimes a rough estimate of the source dimensions) may be determined by joint analysis of the data from many stations using averaged relations from a geophysical data set-primarily travel-time and amplitude curves. At the same time, residuals are determined for some phases. Confidence ellipses a re aivertermined.

Source parameters (mainly hypocentral coordinates) give additional criteria for signal (phase) identification. Thus final identification of the signal follows determination of some source parameters, e.g., hypocentral coordinates. Obviously, errors may be revealed if the preliminary signal identification is incorrect. It will then be necessary to return to the seismogram to identify new phases or to make more measurements. This shows the interactive nature between the components of the system as depicted in Fig. 8.

\subsection{CONSTRUCT EMPIRICAL RELATIONS (BASIC RULES)}

Determination of source parameters and final-phase identification from observatic nal data are based on a priori geophysical and geological data co ıtained in this data set. Thus complete analysis of seismograms renuires the construction or updating or both of a data set. For seismic monitoring a necessary data set or set of empirical and analytical relations follows:

(1) Seismir-wave kinematics: travel as a function of epicentral distance and focal depth (travel time curves); dispersion curves, the periods of the earth's free oscillations; uncertainties in these relationships.

(2) Seismic-uave dynamics: seismic-wave amplitude or spectrum as a function $\int$ distance and source depth (amplitude curves); attenuation of surface-wave and free-oscillations amplitudes. The development of these relationships will require analytical studies on wave propagation in anelastic media.

(3) Energy partinioning between phases: body-wave magnitude $(\mathrm{mb})$ vs surface-wave magnitude $\left(\mathrm{M}_{\mathrm{s}}\right)$ curves for earthquakes and explosions (regional and teleseismic); magnitude vs yield curves for explosions (seismic scaling ' $\mathrm{i} w \mathrm{~W}$ ); a collection of seismic discrimination and evasion relations and their limitations.

(4) Network-capability curves: contour plots of the detection capability of a network; plots of confidence-ellipse areas for epicenter location; standard Jeviations for observational data from network stations relative to travel-time curves; station locations and noise levels; noise and signal variances. These data are particularly needed for locating seismic sources and for accessing uncertainties in locations from a particular network.

(5) Seismicity maps: distribution of earthquake hypocenters with various energies or magnitudes; earthquake frequency relations. These are added data that can be used for discriminations within a particular region.

(6) Earth models: intrinsic and structural properties; regional maps of the geological structure and gross geophysical and mechanical properties; effects of geophysics and geochemistry on wave propagation. These models are particularly used in forward calculations to ac:ess the effects of given constitutive properties on waveform.

These operations are done in parallel with the data in stages 5.1 and 5.2 of Fig. 8 and require continuous uf jiaing as knowledge of earth structure and seismic sources progresses. They are a necessary part of any general research scheme. 


\subsection{SEISMOLOGICAL CONCLUSIONS}

The conclusions to be drawn from analysis of observation data are (1) the earth's structure: distribution of seismic-wave velocities, density, and attenuation; (2) source physics: investigation of mechanisms that casse seismic radjations; and (3) source idenificarion: location, origin time, energy, and size.

These conclusions are based on an inaccurate and incomplete data set and are probabilistic in nature. Depending on data accuracy, on the method of solution, and on the starting values, any number of solutions or no solution may be obtained. The problem in any inverse problem is to seek not a unique solution, but its distribution function within a set of possible solutions. The trial-and-error method is most appropriate as it is equipped to span the entire parameter space. However, as shown in Table 3, this requires a significant amount of computation time.

\subsection{GENERAL ANALYSIS CODE}

The system for analysis of seismic data depicted in Fig. 8 may be combined into an interactive general purpose computer code. The general purpose code is designed to be a controller for a set of subprograms. Depending on the application, it can call any program or data file in the set. The general system may also be used to provide guidance for program research.

\section{Component Subprograms}

These component programs are listed as ordered by the flow diagram depicted in Fig. 8.

(1) Analysis of seismogram. This is a collection of subroutines for the initial processing of a seismogram. Some subroutines or research areas that may be included in the analysis follow:

(a) Algorithıns for detecting a seismic signal against background.

(b) Frequency-analyses routine.

(c) Time-windowing routine.

(d) Instrument-response routine.

(e) Convolution routine.

(f) Algorithm to determine relative amplitude of phases, arrival times, etc. Tull [personal communication, 1978] is developing a general analysis code for seismograms, SAC. Routines developed in this code can be used in the above set. Codes from Robinson's (1966) package also apply.

(2) Initial analysis of source. A set of subprograms for initial analysis of the source.

(a) Location algorithm.

(b) Algorithm for determining magnitudes of body and surface waves.

(c) Statistics of local earthquake catalogs, i.e., elgorithm for computing the probability of occurrence of local earthquakes of given magnitude and depth.

(d) Algorithm for yield determination.

(3) Added inversion algorithms. A set of programs used to determine added parameters necessary to either describe the gross properties of the earth or the seismic source. These operations are only necessary if, in locating the source (an inverse problem), not enough information is obtained to identify it. in many cases the source is identified from the depth of its hypocenter.

(a) Integral-transform codes for wave propagation in layered media in both two and three dimensions.

(b) Parameter-search algorithms (minimization codes).

(c) Generalized matrix-inversion routines.

(d) Finite-difference code.

(e) Finite-element code.

(f) Method-of-characteristics code. 
(4) Data Summary. Collection of seismological data files, maps, and hard-cover summary of geophysical and seismological data. These data obviously vary on a regional scale and are by no means comprehensive.

\section{Data flles}

(a) Travel-time tables.

(b) Dispersion relations.

(c) Periods of earth's free oscillations.

(d) Amplitude relations, including attenuation.

Maps

(a) Seísmicity maps.

(b) Regional geological structure.

(5) Hard-Cover Summary. This is a collection of the empirical relations and data summary presented in Section 5.3.

All data files and computational algorithms necessary to complete an interactive computer code or a seismic-monitoring research system are definitely not included in this section. It has not been my intent to do so. The main intent of this section is to lay out a general framework for continued research in developing the system.

The input to the general analysis code is in the form of data files: seismic-station locations; combinations of the seismic observations, including noise levels; the earth's structure; seismic-wave velocities; attenuation; and a description of source and its location, depending on the problem to be solved. The general analysis code (system) is designed to be user-interactive and to perform two major functions: (1) invert seismological data or (2) use as a framework to study the effect of the earth's structure; of its geophysical, geochemical, and mechanical properties; and of the source-time function on seismic-wave propagation. Figure 9 shows the flow diagram for the general anulysis code. The major effort of LLL's seismic-monitoring iesearch program required to complete the general analysis code outlined in this report lies in structural organization; developing data files; developing forward-wave-propagation algorithms; inversion algorithms; and inputoutput routines. Many of these routines already exist at LLL, and some were presented earlier in this report.

\section{DISCUSSION AND RECOMMENDATIONS}

The basic aim of the system for seismological computations described above is to present a methodology to obtain optimum and consistent (with entire data) values of seismir ource parameters. It is developed in terms of a logical ondering of the data analysis. Seismological conclusis ts obtained from the analysis require the joint analyses of observational data, previously established anulytical and empirical relations, and a data set. The general system conveniently divides into two parts: (1) inversion of observational data and (2) general computations to assess the effect of the energetic parameters of the source and the earth's structure on seismic-wave propagation.

I present two methods for obtaining a solution to the inverse problem. The inverse problem is solved to obtain the source location, the source mechanism and yield, and the earth's structure. These are not all done simultaneously, but each represents an inverse problem. The flow diagrams of the codes necessary to obtain the inverse solution were in the previous section. Once an estimator is obtained [Eq. (1) for example], the ilverse problem is basically concerned with the development of mathematical algorithms for parameter estimation subject to a priori constraints. These constraints depend on the physical processes involved. Conclusions reached from any inversion scheme based on insufficient and inaccurate data contain uncertainties. The region of uncertainty is developed in the inversion scherse. How sensitive these conclusions are to uncertainties in seismological measurements, the distribution of seismic stations, or one's ignorance of the physical phenomenon and earth models are things to be addressed in the general research program. The accuracy of the inversion of seismological data rests on the adequacy and completeness of the data summary and how well the estimators model the physical phenomenon. 


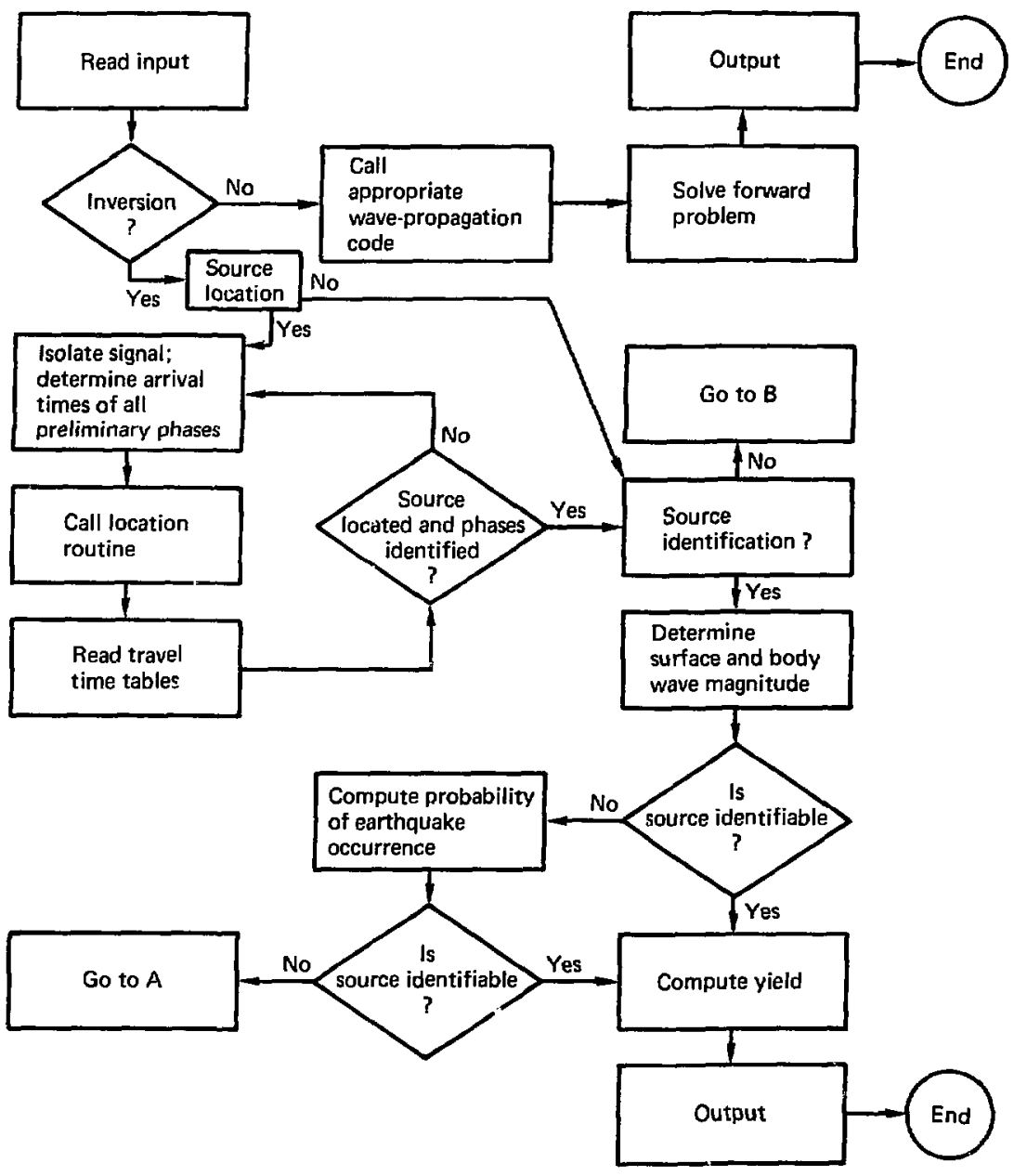

FIG. 9. Flow diagram for general seismological computations. 


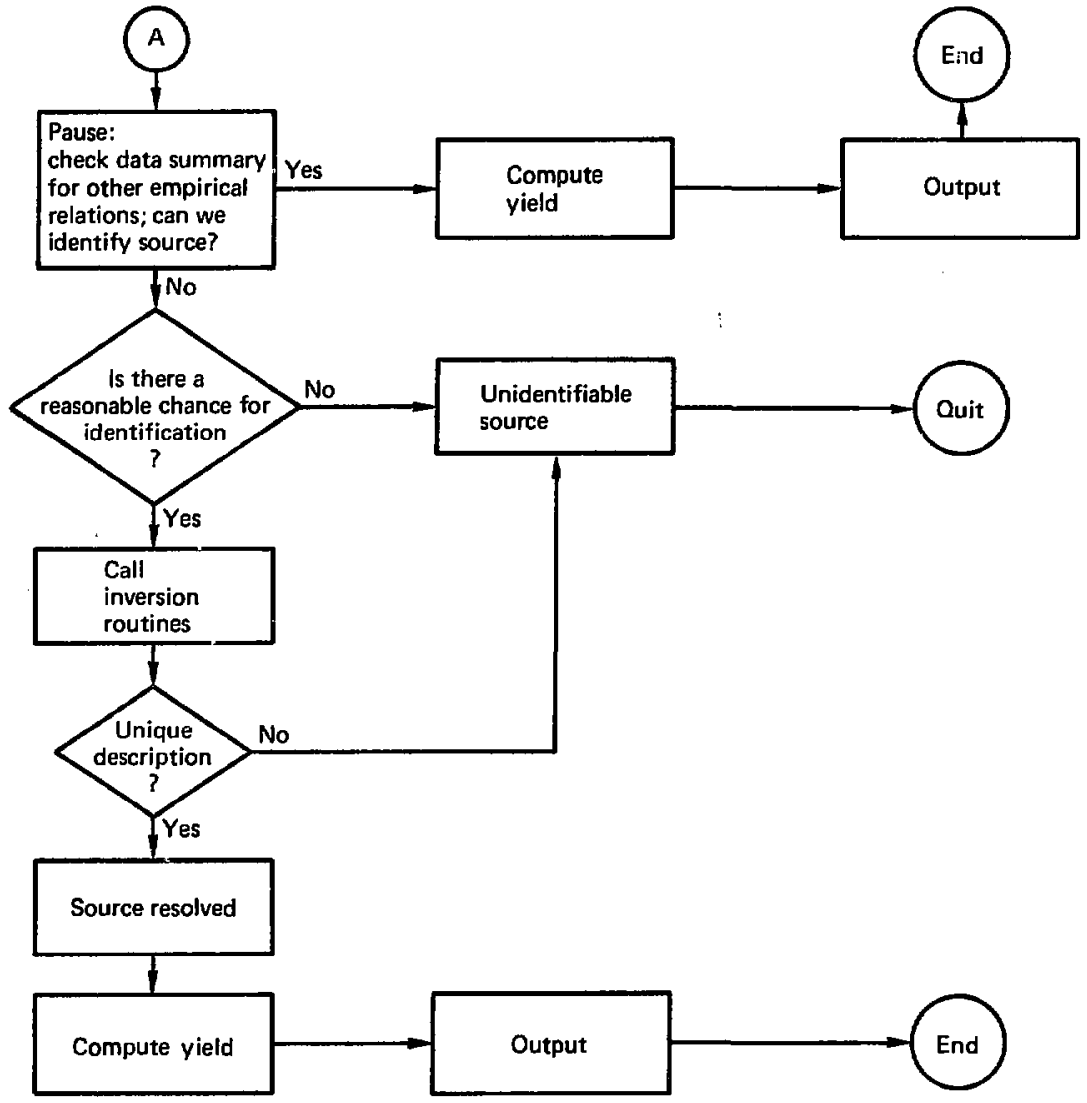

FIG.9. Continued. 


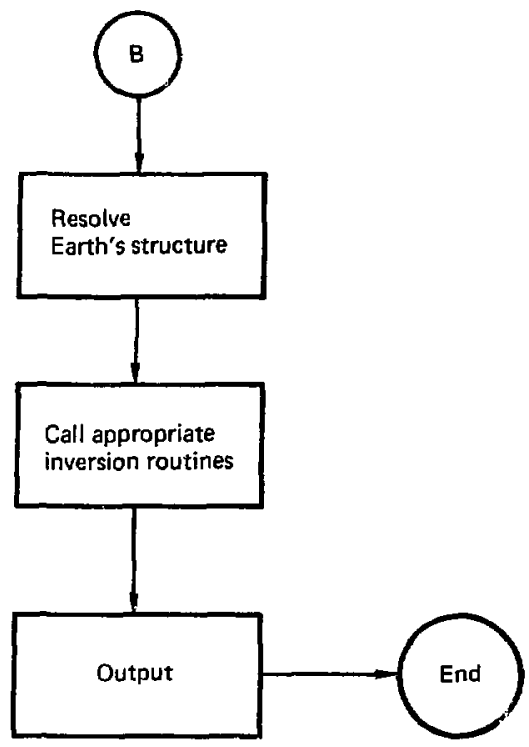

FIG. 9. Continued.

Constraints on model parameters are usually derived from both laboratory and field experiments. Assessments of variations in the parameters on material response are obtained from direct calculations in the forward solution. In seismology, numerical solutions to the forward problem may be obtained by finite difference, finite elements, integral transforms, and the methrd of characteristics.

LLL has performed finite-difference calculations using the SOC code to determine reduced displacement potentials (seismic-source functions) for underground explosions. This representation is strictly valid only for spherical-wave propagation in an unbounded medium. Free surfaces, material boundaries, gravitation, depth of source, etc. affect the sphericity assumption. In fact, not enough close-in experimental data exist for valid comparisons; a general assessment of computational models awaits these data. The few comparisons of calculations with experimental data have used parameter adjustment to compare with close-in data [Cherry and Petersen, 1970]. Presently researchers are not able to descirbe the details of motion resulting from explosions with this code without parameter adjustments [Schatz et al., 1977]. The calculations require a prohibitive amount of time, and hence no complete finite-difference calculations exist from the source region to distances where the seismograms are recorded. For these reasons, one cannot assess the adequacy of material models used in seismic-monitoring research. This again points to the need for developing techniques to use finite-difference calculations as input to integral-transform codes.

Finite-difference calculations may be used for a limited parameter study to assess some important behavior that cannot be obtained from empirical studies or other means. These calculations may also provide source functions for integral-transform codes. These studies would include an assessment of the effects of boundaries near the source, water tables, porosities, material strength, etc. and the effects of source depth on the seismogram spectrum. Correlation of these results with experimental data for different material models and rock types will lead to some understanding of how well one needs to model a particular region and how much information can be obtained from a seismogram. These studies require both one-and two-dimensional calculations, which at present have not been performed. The SOCand TENSOR codes are considered for this purpose. 
For earthquake sources, a three-dimensional finite-element or finite-difference code may be used for the same purposes. With the incorporation of a time-dependent boundary condition allowing a displacement discontinuity or stress drop. TENSOR may be used to model earthquakes when a two-dimensional representation is adequate. The large finite-difference or finite-element codes should not be used alone for sensitivity analysis, because of the prohibitive number of calculations necessary for this analysis. Instead, a general sensitivity algorithm should be developed and used in parallel to make most efficient use of resources. Cukier er al., (1978) have given a clear, detailed discussion on sensitivity analysis in a review article.

The method of characteristics is the natural method to study the wave-interaction problems and to provide a physical understanding of the processes. This method requires considerable programming. For the general constitutive models that may be considered in the inmediate vicinity of a nuclear explosion this method secms inapplicable. No theory is developed for determining compatability relations across discontinuities for the general constitutive relations that may arise in these studies. Only shock theory for conservation laws is devcloped. (For practical reasons, this method cannot replace the finite-difference technique.) Again I do not consider its usc in the general inversion scheme. I suggest the method of characteristics for use in understanding t'ie physics of certain wave-interaction problems.

Integral-transform methods are widely used in computing synthetic seismograms and in seismicinversion studics. However, these methods are applicable for solutions to linear problems. Thus one can only obtain an cquivalent elastic representation for the seismic source from inversion studies. The equivalent-source or force-moment tensor is only a mathenatical representation of the source [Randall, 1971; Backlus and Mulcuhy, 1976]. The interpretation of this representation in regions of wave interactions from s zveral sources and material boundary effects requires detailed analyses of the physical model of the source. This analysis presently docs not exist for nonspherically symmetric explosive sources. To obtain a detailed assessment of the nonlinear phenomenon, nonlinear problems must be solved and should be the subject of future research. Hence I suggest the use of finite-difference, finite-element, and the method-of-characteristics codes for developing qualitative and quantitative effects of material properties and boundaries in the near-source region and not as the estimator for inversion studies. Integral-transform codes are most relevant for inversion studies and for use in studying path effects of waves propagating in geologic media.

I lasve discussed development of a system to study problems in seismic monitoring and suggest that it requires an understanding of the whole geophysical problem (particularly in developing a data summary) as some non-scismic element may be important when interpreting results. The data summary is the most impor:ant part of the system as it is necessary for any inversion scheme ${ }^{-} \mathrm{d}$ should represent the most active area of research. Errors in this summary, particularly for the earth model, necessarily will lead to incorrect interpretation from an inversion scheme.

In a general systems study, sensitive areas must be isolated and related to the information stream. I am not aware of any detailed analyses of wave propagation from explosive or earthquake sources to distances where seismograms clearly isolate sensitive areas in the information stream. 'To isolate these sensitive areas, an immediate computational effort should be in the generation of synthetic response for understanding the physics of wave interactions in the linear and nonlinear regions of the problem. This requires analyses for interpretation of the nonlinear region as equivalent elastic sources, particularly how source geometry, free surface: and artificial boundaries affect the response at distance. Further, one must understand the effects of diffe rent inaterial models on the seisrsic response. Only then can one unequivocally state how important is the nonlinear-source region in seismic-monitoring research. I will now discuss some specific problems and computational methods to address these questions.

I propose a general study of the effects of material models, source geometry, and material boundaries on the seismic response. Finite-difference or finite-element codes may be used to compute the response in the nonlinear region to obtain equivalent elastic-source representations. These equivalent elastic sources may be used as input to integral-transform codes for computing the response at large distance from the source. This study reduces to an assessment of how sensitive the seismogram is to material models, source geometry, and material boundaries within the region of interest; it leads to an interpretation of seismograms based on these effects. One particular aspect of the general study to be addressed is an understanding of the generation of the 
fundamental Rayleigh Mode as it is important for seismic-discrimination purposes. Here I suggest the use of phenomenologica! source descriptions, with simple earth models using the metiod of characteristics as the solution technique. I considered the method of characteristics because it is the natural technique to study wave-interaction problems.

A second aspect of this study that should be addressed in the immediate future is the partitioning of energy in $\mathrm{P}$ and $\mathrm{S}$ waves. This energy partitioning has relevance to developing regional seismic-discrimination relations and in developing a thorough understanding of how certain regional phases develop. Again 1 propose that simple earth models be used. However, the suggested solution techniques are the method of characteristics, surface-wave-mode summation, and integral-transform methods for body waves in layered media.

Simultaneousiy. I propose that continued effort be maintained in updating the data summary discussed in Section 5.3. This includes inversion of seismological data from known explosive sources to establish credibility of inversion schemes and to refine regional earth models. Once models are obtained, these should be used to inver data to see how well one can determine the parameters of known sources from observational data using the given earth model. Moreover. continued effort must be expended in seismic-source theory. Further experimental efforts in modeling material behavior are necessary to develop appropriate constitutive models for rock and rock-like materials. I consider the above to be immediate tasks; they will lead to the definition of new problem areas.

\section{SUMMARY AND CONCLUSIONS}

The forward and inverse problems of seismology are examined in the context of seismicmonitoring research. Mcthods used to formulate these problems are examined and solution techniques compared. From this examination I conclude that no solution technique or method is equally valid for all domains of interest in the problems outlined in this report. I further conclude that not enougi close-in experimental data or analyses or both exist for an assessment of the adequacy of constitutive models used in seismic-monitoring research. Continued efforts are required in this area. Moreover, no review of an area as broad as seismic monitoring can be completely comprehensive.

I discussed the formulation of the inverse problem to account for the statistical nature of measurements and the limited knowledge of the earth's structure. And, a set of computer codes (system) for solution to these problems was presented and their physics and limitations were discussed. My main purpose was to propose a unified methodology for analyzing seismic data for developing an overall computational capability for seismic-motitoring research. I developed the system in terms of a logical ordering of data analysis. From this ordering, the flow diagram for a general analysis code was developed. Furthermore some necessary subprograms to complete the general analysis code were described. The general analysis outlined may be used either for processing of observations (seismic monitoring) or for generalizations in terms of physical processes (research). Much effort is needed to complete the general computational capability. The main advantage of the system outlined here is that it unifies computational and research efforts.

\section{ACKNOWLEDGMENTS}

I am indebted to R. C. Y. Chin for many enlightening discussions on numerical-analysis pnd wavepropagation problems and for his helpful comments on the organization and contents of this report. 1 am indebted to $\mathbf{H}$. C. Rodean for his suggestion that I write this report and for a subsequent critical review of the manuscript. I am also grateful to P. Brown, D. B. Burton, A. Duba, J. Hannon, J. Mills, K. Nakanishi, and $\mathbf{H}$. Patton for their critical review of the manuscript and for their helpful suggestions for the improventent of its contents. Several general discussions with selected rembers of the Applied Physics and Mechanics section and of the Seismology Group of K-Division are acknowledged. General discussions with $\mathbf{M}$. S. Costantino, D. H. Chung, and D. B. Larson on the seismic monitoring program are also acknowledged. 


\section{REFERENCES}

Abramovici, F., 1978. A Generalization of the Cagniard Method, J. Comput. Phys., 29, 328-343.

Aki, K., 1967. Scaling Law of Seismic Spectrum, J. Geophys. Res., 72, 1217-1231.

Aki, K., M. Bouchon, and P. Reasonberg, 1974. Seismic Source Function for an Underground Nuclear

Explosion, Bull. Seismol. Soc. Am., 64, 131-148.

Anderson, D. L., 1975. Structure of the Mantle, Rev. Geophys. and Space Phys., 13, 300-302.

Anderson, G. D. and D. B. Larson, 1976. Shock-Wave Studies of Subbituminous Coals, Lawrence Livermore

Laboratory, Livermore, CA 94550, UCRL-51996.

Anderson, G. D. and D. B. Larson, 1977. Plane Shock Wave Studies of Geologic Media, Lawrence Livermore

Laboratory, Livermore, CA 94550, UCRL-52357.

Andrews, D. J. and S. Shlien, 1972. Propagation of Underground Explosion Waves in the Nearly r:lastic

Range, Bull. Seismol. Soc. Am., 62, 1691-1t.98.

Archambeau, C. 1975. Developments in Seismir. Source Theory, Rev. Geophys. and Space Phys., 13, $304-306$.

Archuleta, R. J. and G. A. Frazier, 1978. Three-Dimensional Numerical Simulations of Dynamic Faulting

in a Half-Space, Bull. Seismol. Soc. Am., 68, 54l-572.

Asbel. I., Ya., V. I. Keilis-Borok, and T. B. Yanovskaja, 1966. A Technique of a Joint Interpretation of Travel-

Time and Amplitude-Distance Curves in the Upper Mantle Studies, Geophys. J. R. Astr. Soc., 11, 25-55.

Backus, F. and F. Gilbert, 1968. The resolving power of gross earth data, Geophys. J. R. Astr. Soc., 16, 169-205.

Backus, G. and M. Mulcahy, 1976. Moment tensors and other Phenomenological Descriptions of Sejsmic

Sources-I. Continuous Displacements, Geophys. J. R. Astr. Soc., 46, 341-361.

Balk, P. I., 1977. Contribution to the Theory of the Trial and Error Method in Solving the Three-Dimensional

Inverse Gravity Problem, Sov. Geol. and Geophys., 18, 7-282.

Bard, Y., 1974. Nonlinear Parameter Estimation, Academic Press, New York.

Benioff, H., 1964. Earthquake Source Mechanisms, Science, 143, 1399-1406.

Boore, D. M., 1972. Finite Difference Methods for Seismic Wave Propagation in Heterogeneous Materials, Methods in Comput. Phys., 11, Academic Press, New York, 1-37.

Brillouin, L. 1960. Wave Propagation and Group Velocity, Academic Press, New York.

Bryan, J. B., D. E. Burton, M. E. Cunningham, and L. A. Lettis Jr., 1978. A Two-Dimensional Computer

Simulation of Hypervelocity Impact Cratering: Some Preliminary Results for Meteor Crater; Arizona,

Lawrence Livermore Laboratory, Livermore, CA 94550, UCRL-80539.

Budyanskii, Y. A., A. V. Kudrya, N. I. Ogurtsov, and A. A. Chekasin, 1975. Determination of a Seismic

Section by the Wave Reflection Method, USSR Comp. Math. and Math. Phys., 15, 200-208.

Buland, 1976. The Mechanics of Locating Earthquakes, Bull. Seismol. Soc. Am., 66, 173-187.

Buland, R. and F. Gilbert, 1976. Matched Filtering for Seismic Moment Tensor, Geophys. Res. Lett., 3, 205-206.

Burridge, R. 1976. Some Mathematical Topics in Seismology, Courant Institute of Mathematical Sciences, New York University, New York.

Burton, D. E. and J. F. Schatz, 1974. Rock Modeling in TENSOR 74, Lawrence Livermore Laboratory, Livermore, CA 94550, UCID-16719.

Burton, D. E., L. A. Lettis, J. B. Bryan, T. R. Butkovich, and A. L. Bruce, 1n77. Anisotropic Creation and Closure of Tension Induced Fractures, Lawrence Livermore Laboratory, Livermore, CA 94550, UCR L79578. Preprint, Proc. Am. Nucl. Soc. Topical Mig. Energy and Mineral Resource Recovery Res., April 12-14, 1977, Golden, Coloradu.

Butkovich, T. R., 1965. Calculations of the Shock Wave from an Underground Nuclear Explosion in Granite, J. Geophys. Res., 70, 885-892.

Butkovich, T. R., 1967. The Gas Equation of State for Natural Materials, Lawrence Livermore Laboratory, Livermore, CA 94550, UCRL-14729.

Butkovich, T. R. and A. E. Lewis, 1970. Aids for Estimating Effects of Underground Nuclear Explosions, Lawrence Livermore Laboratory, Livermore, CA 94550, UCRL-50929. 
Butkovich, T. R., 1971. Effects of Water Saturation on Underground Nuclear Detonations, Lawrence Livermore Laboratory, Livermore, CA 94550, UCRL-51110.

Butkovich, T. R., 1973. A Technique for Generating Pressure-Volume Relationships and Failure Envelopes for Rocks, Lawrence Livermore Laboratory, Livermore, CA 94550, UCRL-5144I.

Carpenter, E. W., 1967. Teleseismic Signals Calculated for Underground, Underwater and Atmospheric Explosions, Geophysics, 32, 17-32.

CCD/558, 1978. Report to the Conference of the Committee on Disarmament of the AD HOC Group of Scientific Experts to Consider International Co-operative Measures to Detect and to Identify Seismic Events, Conference of the Committee on Disarmoment. GE. 78-83072, Geneva.

Chapman, C. H. and R. A. Phinney, 1972. Diffracted Seismic Signals and Their Numerical Solution, Methods in Comput. Phys., 12, Academic Press, New York, 166-230.

Chapman, C. H., 1976. A first motion alternative to geometrical theory, Geophys. Res. Lett., 3, 153-156.

Chapman, C. H., 1978. A New Method for Computing Synthetic Seismograms, Geophys J. R. Astr. Soc., 54, 481-518.

Cherry, J. T. and W. R. Hurdlow, 1966. Numerical Simulation of Seismic Disturbances, Ge aphys., $31,33$.

Cherry, J. T., 1967. Computer Calculations of Explosion-Produced Craters, Int. J. Rock Mech. Mining Sci., 4, i.

Cherry, J. T. and F. L. Petersen, 1970. Numerical Simulation of Stress Wave P-opagation from Underground Nuclear Explosions, Peaceful Nuclear Explosions, Phenomenology and Status Report, International Atomic Energy Agency, Vienna, 1970, 241-325.

Cherry, J. T., S. Sack, G. Maenchen, and V. Kransky, 1970. Two-Dimensional Stress-Induced Adiabatic Flow, Lawrence Livermore Laboratory, Livermore, CA 94550, UCRL-50987.

Cherry, T., R. N. Schock, and J. Sweet, 1975, A Theoretical Model of the Dilatant Behavior of a Brittle Rock, Pageoph., 113, 183-196.

Cherry, J. T., T, C. Bache, C. B. Archambeau, and I). G. Harkrider, 1974. A Deterministic Approach to the Prediction of Telesejsmic Ground Motion from Nuclear Explosions, Defense Documentation Center, Alexandria, VA, DNA $3321 \mathrm{~F}$.

Chin, R. C. Y., 1975. Dispersion and Gibbs Phenomenon Associated with Difference Approximations to Initial Boundary-Value Problems for Hyperbolic Equations, J. Comput. Phys., 18, 223-247.

Chin, R. C. Y. and G. W. Hedstrom, 1976. Uniform Asymptotic Expansions for Numerical Solutions of Hyperbolic Equations, SIAM-AMS Proc., 10, 145-146.

Chin R. C. Y. and G. W. Hedstrom, 1978. A dispersion Analysis for Difference Schemes: Tailes of Generalized Airy Functions, Math. Comp., 32, 1163-1170.

Choy, G. L., 1977. Theoretical Seismograms of Core Phases Calculated by Frequency-Dependent Full Wave Theory, and Their Interpretation, Geophys. J. R. Astr. Soc., 51, 275-312.

Chung, D. H., 1978. Parametric Studies of the Earth's Upper Mantle, Lawrence Livermore Laboratory, Livermore, CA 94550, UCRL-81713.

Claerbout, J. F. and F. Muir, 1973. Robust Modeling with Erratic Data, Geophys., 38, 826-844.

Clayton, R. W. and R. A. Wiggins, 1976. Source Shape Estimation and Deconvolution of Teleseismic Body Waves, Geophys. J. R. Astr. Soc., 47, 151-177.

Clifton, R. J., 1967. A Difference Method for Plane Problems in Dynamic Elasticity, Q. Appl. Mech., 25, 97-116.

Costantino, M. S. and R. N. Schock, 1976. A Constitutive Relation for Compressive Loading in Nuggest Sandstone, Lawrence Livermore Laboratory, Livermore, CA 94550, UCRL-52936.

Costantino, M. S., 1978. Statistical Variation of Stress-Volumetric Strain Behavior of Westerly Granite, Int. J. Rock Mech. Min. Sci. and Geomech. Abstr., 15, 105-111.

Courant R. and D. Hilbert, 1962. Methods of Mathematical Physics, II, Partial Differential Equations by R. Courant, Interscience, New York.

Crosson, R. S., 1976a. Crustal Structure Modeling of Earthquake Data, 1, Simultaneous Least Squares Estimation of Hypocenter and Velocity Parameters, J. Geophys. Res., 81, 3036-3046. 
Crosson, R. S., 1976b. Crustal Structure Modeling of Earthquake Data, 2, Velocity Structure of the Puget Sound Region, Washington, J. Geophys. Res., 81, 3047-3050.

Cukjer, R. 1., H. B. Levine, and K. E. Shuler, 1978. Nonlinear Sensitivity Auralysis of Multiparameter Model Systems, J. Compur. Phys., 26, 1-42.

Dahlman, O. and H. Israelson, 1977. Monitoring Underground Nuclear Explosions, Elsevier Scientific Publishing Company, Amsterdam.

Douglas, A., J. A. Hudson, P. D. Marshall, and J. B. Young, 1974. Earthquakes that look like explosions, Geophys. J. R. Astr. Soc., 36, 227-233.

Dzie wonski, A. M. and F. Gilbert, 1974. Temporal Variation of the Seismic Moment Tensor and the Evidence of Precursive Compression for Two Deep Earthquakes, Nature, 247, 185-158.

Engdahl, E. R., Driewonski, A. M. and E. A. Flinn, 1975. Structure of the Earch's Core, Rev. of Geophys. and Space Phis., 13, 302-303.

Eringen, A. Cemal, 1962. Nonlinear Theory of Continuous Media, McGraw-Hill, San Francisco.

Eringen, A. Cemal, and E. S. Suhubi, 1975. Elastodynamics, II, Linear Theory, Academic Press, New York.

Evernden, J. F., 1967. Magnitude Determination at Regional and Near-Regional Distances in the United States, Bull. Seismol. Soc. Am. 57, 591-639.

Evernden, J. F., 19ú9. Precision of epicenters ebtained by small numbers of world wide stations, Bull. Seismol. Sor. Ain., 59, 1365-1398.

Evernden, J. F., W. J. Best, P. W. Pomeroy, T. V. McEvilly, J. M. Savino, and L. R. Sykes. 1971. Discrimination between small-magnitude earthquakes and explosions, J. Geophys. Res., 76, 8042-8055.

Evernden, J. F., 1977. Adequacy of Routinely Available Data for Identifying Earthquakes of $\mathrm{mb}_{\mathrm{b}}>4.5, \mathrm{Bull}$. Seismol. Sac. Am., 67, 1099-1151.

Flinn, E. A., 1965. Confidence Regions and Error Determination for Seismic Event Location, Rev. Geophys., 3, 157-185.

Frazier, G. A. and C. M. Petersen, 1974. 3-D Siress Wave Code for the ILLIACIV, Systems, Science and Software, La Jolla. CA, SSS-R-74-2103.

Fuchs, K. and G. Müller, 1971. Computation of Synthetic Seismograms with Reflectivity Method and Comparison with Observations, Geophys. J. R. Astr. Sor., 23, $417-433$.

Frosch, R. A. and P. E. Green, Jr., 1966. The Concept of a Large Aperture Seismic Array, Proc. Roy. Soc. (London), Sec. A, 290, 368.

Garg, S. K., 1971. Wave Propagation Effects in a Fluid-Saturated Porous Solid, J. Geophys. Res., 76, 7947-7962.

Geiger, L., 1910. Herdbestimmung bei Erdbeben aus den Ankunftzeiten, K. Gessell, Wiss. Goell., 4, 331-349.

Gilbert, F., 197 la. Inverse Problems for the Earth's Normal Modes, Mathematical Problems in she Geophysical Sciences 2. Inverse Problems, Dynamo Theory and Tides, American Mathematical Society, Providence, RI, $107-127$.

Gilbert, F., 1971b. Ranking and Winnowing Gross Earth Data for Inversion and Resolution, Geophys. J., R. Astr. Soc., 23, 125-128.

Gilbert, F. and R. Buland, 1976. An Enhanced Deconvolution Procedure for Retrieving the Seismic Moment Tensor from a Sparse Nutwork, Geophys. J. R. Astr. Soc., 47, 251-255.

Gustafsson, B., 1969. On Difference Approximations to Hyperbolic Differential Equations Over Long Time Intervals, SIAM J. Numer. Anal., 6, 508-522.

Harkrider, D. G., 1964. Surface Waves in Multilayered Elastic Media I. Rayleigh and Love Waves From Buried Sources in a Multilayered Elastic Half-Space, Bull. Seismol. Sac. Am., 54, 627-679.

Hart, R. S., D. L. Anderson, and H. Kanamari, 1977. The Effect of Attenuation on Gross Earth Models, $J$. Geophys. Res., 82, 1647-1654.

Haskell, N. A., 1953. The Dispersion of Surface Waves on Multilayered Media, Bult. Seismol. Soc. Am., 43, 17-34.

Hedstrom, G. W, 1968. The Rate of Convergence of Some Diffejence Schemes, J. S/AM Numer. Anal., 5, 363-406. 
Helmberger, D. V. and R. Wiggins, 1971. Upper Mancle Structure of Midwestern United States, J. Geoph's. Res., 76, 3229-3245.

Helmberger, D. V., 1972. Long-period body-wave propagation from 4 degrees to 13 degrees, Bull. Seismal. Soc. Am., 62, 325-341.

Helmberger, D. V., 1973a. Numerical Seismograms of long-period body waves from seventeen to forty degrees. Bull. Seismol. Soc. Am., 63, 633-646.

Helmberger, D. V., 1973b. On the Structure of the Low Velocity Zone, Geophys. J. R. Astr. Soc., 34, $251-263$. Helmberger, D. V. and G. R. Engen, 1973. Upper Mantle Shear Struiture, J. Geophys. Res., 79, 4017-4028. Helmberger, D. V.. 1974. Generalized Theory for Shear Dislocations, Bull. Seismol. Soc. A. a., 64, 45-64.

Herrin, E. and J. Taggart, 1962. Rezional Variations of $P_{n}$ Velocity and Their Effect on the Location of Epicenters, Bull. Seismol. Soc. Am., 52, 1037-1046.

Herrin, E., 1968. 1968 Seismological Tables for P Phases, Bull. Seismol. Soc. Am., 58, 1223-1225.

Herrmenn, R. B. and O. W. Nuttli, 1975a. Ground Motion Modeling at Regional Distances for Earthquakes in a Continental Interior, I. Theory and Observations, Earthquake Eng. and Strucrural Dynamics, 4, 49-58.

Yermann, R. B. an 1 O. W. Nuttli, 1975b. Ground Motion Nodeling at Regional Distances for Farthquakes in a Continental Interior, II. Effect of Focal Depth, Azimuth and Attenuation, Earthquake Eng. and Structural Dymamics, 4, 59-72.

Hoskin, N. E., 1964. Solution by Characteristics of the Equations of One-Dimensional Unsteady Flow, Methods in Comput. Phys., ?. Academic Press, New York, 265-293.

Holzer, F., 1966. Calculation of Scismic Source Mechanisms, Proc. Roy. Soc. (London), Ser. A. 290, 408-429. Hudson, J. A., 1969a. A Quantitative Evaluation of Seismic Signals at Teleseismic Distances-l. Radiation from Point Sources, Geoph, s. J. R. Astr. Soc, 18, 233-249.

Hudson, J. A., 1969b. A Quantitative Evaluation of Seismic Signals at Teleseismic Distances-Il. Body Wayes and Surface Waves from an Extended Source, Geophys. J. R. Astr. Soc., 18, 353-370.

Jackson, D. D., 1972. Interpretation of Inaccurate, Insufficient and Inconsistent Data, Geophys. J. R. Astr. Soc., 28, 97-109.

Jackson, D. D., 1973. Marginal solutions to quasi-linear inverse problems in geophysics: the edgehog method, Geophys. J. R. Astr. Soc., 35, 121-136.

Johnson, Lane R., 1974. Green's Function for Lamb's Problem, Geophys. J. R. Astr. Soc.. 37, 99-131.

Johnson, L. E. and F. Gilbert, 1972. Inversion and Inference for Teleseismic Ray Data, Methods in Comput. Phys., 12, Academic Press, New York, 231-266.

Jurdan, T. H. and J. N. Franklin, 1971. Optimal Solutions to a Linear Inverse Problem in Geophysics, Proc. Nat. Acad. Sc! USA, 68, 29I-293.

Kanamori, H., 1970. Synthesis of Long-Period Surface Waves and Its Application to Earthquake Source Studies-Kurile Islands Earthquake of October 13. 1963, J. Geophys. Res., 75, 5011-5027.

Kanamori, H. and D. L. Anderson, 1977, Importance of Physical Dispersion in Surface Wave and Free Oscillation Problems: Review, Rev. Geophys. and Space Phys., 15, 105-122.

Karpp, R. and P. C. Chou, 1972. The Method of Characteristics, Dynamic Response of Materials to Intense Impulsive Loading, P. C. Chou and A. K. Hopkins, Eds., Air Force Materials Laboratory, Wright Patterson AFB, Ohio 45433, Chapter 6.

Keilis-Borok, V. I., 1972. Seismology and Logic, Computotional Seismology, V. I. Keilis-Borok Ed., translated from Russian by S. B. Dresner; translation edited by E. A. Flinn, Consultants Bureau, New York, 1-9.

Keller, J. E. and J. S. Papadakis, 1977. Wave Propagation and Underwater Acoustics, Lecrure Nores in Physics, 70, Springer-Verlag, New York.

Kennett, B. L. N., 1974. Reflections, Rays, and Reverberations, Bull. Seismol. Soc. Am., 64, 1685-1696.

Lan :zos, C., 1961. Linear Differential Operators, D. Van Nostrand Co., London.

Langston, C. A. and D. V. Helmberger, 1975. A Procedure for Modeling Shallow-Dislocation Sources, Geophys. J. R. Astr. Soc., 42, 117-130.

Lapwood, E. R., 1949. The Disturbance Due to a Line Source in a Semi-Infinite Elastic Medium, Phil. Trans. R. Soc, 242A, 63-100. 
Larson, D. B., 1977a. The Relationship of Rock Properties to Explosive Energy Coupling, Lawrence Livermore Laboratory, Livermore, CA 94550, UCRL-52204.

Larson, D. B., 1977b. Explosive Enerzy Coupling in 15 Geologic Materials, Lawrence Livermore Iaboratory, Livermore, CA 94550, UCRL-79427, submitted Geophys. J. R. Asli. .jur.

Larson, D. B. and G. D. Anderson, 1978. Plane Shock-Wave Studies of Porous Geologic Media, Lawrence Livermore Laboratory, Livermore, CA 94550, UCRL-80898, submitted J. Geophys. Res.

Larson, D. B. and H. C. Rodean, 1975. The Relationship of Material Propersies to Seismic Coupling. Part I: Shock Wave Studies of Rock and Rock-Like Materials, Lawrence Livermore Laboratory, Livermore. CA 94550, UCRL-51769.

Latter, A. L., E. A. Martinelli, and E. Teller, 1959. Seismic Scaling Law for Underground Explosions, Phys. Fluids, 2, 280-282.

Latter, A. L.. R. E. Lelevier, E. A. Martinelli, and W. G. McMillan, 196t. Method of Concealing Underground Nuclear Explosions, J. Geophys. Res., 66, 943-946.

Lee, W. H. K. and J. C. Lahr, 1975. HYPO7I (Revised): A Computer Program for Determining Hypocenter. Magnitude, and First Motion Pattern of Local Earthquakes, U.S. Geological Survey Open File Report 75-311, United Department of the Interior Geological Survey, National Center for Earthquake Research, Menlo Park, CA.

Licbermann, R. C. and P. W. Pomeroy, 1969. Relative Excitation of Surface Waves by Earthquakes and Underground Explosions, J. Geophys. Res., 74, 1575-1590.

Lommitz, C., 1977. A Fast Epicenter Location Program, Bull. Seismol. Soc. Am., 67, 425-531.

Lysmer, J. and L. A. Drake. 1972. A Finite Element Method for Seismology, Methods in Comput. Phys., 11, Academic Press, New York, 181-216.

Maenchen, G. and S. Sack, 1964. The Tensor Code, Methods in Comput. Phys., 3, Academic Press, New York, 181-210.

Marshall, P. D., 1970. Aspects of the specirá! differences between earthquakes and underground explosions, Geophys. J., 20, 397-416.

Marshall, P. D. and P. W. Besham, 1972. Discrimination between earthquakes and underground explosions employing an improved $\mathrm{M}_{5}$ scale, Geophys. J. R. Astr. Soc., 28, 431-458.

Marshall, P. D., D. L. Springer, and H. C. Rodean, 1978. Magnitude Carrections for Autenuation in the Upper Mantle, Lawrence Livermore Laboratory, UCRL-80423, Submitted Geophy. J. R. Astr. Soc.

McEvilly, T. V. and W. A. Peppin, 1972. Source Characteristics of Earthquakes, Explosions, and Afterevents, Geophys. J. R. Astr. Soc., 31, 67-82.

McMechan, G. A., 1978. Seismic Inversion for the Shape of a Boundary Between Two Layer Stacks, Bull. Seismol. Soc. Am., 68, 599-608.

Mellman, G. R. and D. V. Helmberger, 1978. A Modified First-Motion Approximation for the Synthesis of Body-Wave Seismograras, Geophys. J. R. Astr. Soc., 54, 129-140.

Mitchell, B. J. and D. V. Helmberger, 1973. Shear Velocities at the Base of the Mantle from Observations of S and $\mathrm{S}_{\mathrm{c}} \mathrm{S}$, J. Geophys. Res., 78, 6009-6020.

Molnar, P., J. Sovino, L. R. Sykes, R. C. Libermann, G. Hade, and P. W. Pomeroy, 1969. Small Earthquakes anis Explosions in Western North America Recorded by New High Gain, Long Period Seismographs, Noture, 224, 1268.

Mueller, R. A. and J. R. Murphy, 1971. Seismic Characteristics of Underground Nuclear Detonations, Part I. Seismic Spectrum Scaling, Bull. Seismol. Soc. Am., 61, 1675-1692.

Miiller, G., 1973. Anditude Studies of Core Phases, J. Geophys. Res., 78, 3469-3490.

Murphy, J. R. and R. A. Mueller, 1971. Seismic Characteristics of Underground Nuclear Detonations, Part II. Elastic Energy and Magnitude Determinations, Bull. Seismol. Soc. Am., 61, 1693-1704.

Murphy, J. R., 1977. Seismic Source Functions and Magnitude Determinations for Underground Nuclcar Detonations, Bull. Seismol, Soc. Am., 67, 135-158.

Nersesov, 1. L. and T. G. Routian, 1977. Kinematics and Dynamics of Seismic Waves at Distances up to $3500 \mathrm{~km}$ from Epicenter, Tr. Inst. Fiz. Zamli. Akad. Nauk. SSSR, 32 (199), $63-87$ (1964). Lawrence Livermore Laboratory, Livermore, CA 94550, UCRL-TRANS-11313 (1977). 
Peppin, W. A., 1977. A near-regional explosion source model for tuff, Geophys. J. R. Astr. Soc., 48, $331-349$. Randall, M. J., 1964. On The Mechanism of Earthquakes, Bull. Seismol. Sac. Am., 54, i283-1289.

Randall, M. 3., 1971. Elastic Multiple Theory and Seismic Moment, Bull. Seisnol, Sor. Am., 61, 1321-1326. Recker, W. W., 1970. A Numerical Solution of Three-Dimensional Problems in Dynamic Elasticity. Tran. ASAE J. Appl. Mech., March, 116-122.

Richards, P. G., 1975. Theoretical Seismology, Rev. Geophys. and Space Phys., 13, 295-298.

Richards, P. G.. 1971. Potentials for Elastic Displacement in Spherically Symmetric Media, J. Acoust. Soc. Am., 51. 188-197.

Richards, P. G., 1973. Calculation of Body Waves for Caustics and Tunnelling in Core Phases, Geophys. J. R. Assr. Soc., 35. 243-264.

Robinson, E. A., 1966. Collection of Fortran II Programs for Filtering and Spectral Analysis of Single Channe] Time Series, Geophy's. Prospecsing. If, Appendix.

Rodean, H. C. 1971. Nuclear Explosion Seismology, AEC Critical Review Series, U.S. Atomic Energy Commission, Oak Ridge, Tenn.

Rogers, L. A, 1966. Free-Field Motion Near a Nuclear Explosion in Salt: Project Salmon, J. Geophy's. Res., 71, 3415-3426.

Romney, C. F., 1959. Amplitudes of Seismic Body Waves from Underground Nuclear Explosions. J. Geophys. Res., 64. 1489-1498.

Ryaboy, V. Z.. 1977. Study of the Structure of the Lower Lithosphere by Explosion Seismology in the USSR, J. Geophys., 43, 593-610.

Saito, M., 1967. Excitation of Free Oscillations and Surface Waves by a Point Source in a Vertically Heterogeneous Earth, J. Gcophl's. Res., 72, 3689-3699.

Schaffer, E., D. Springer, and P. Marshall, 1977. Interprezation of $P$ Travel Time Data for NTS-so- $L L L$ Seismic Sianion Paths, Lawrence Livermore Laboratory, Livermore, CA 94550, Earth Sciences (K) Division, Memorandum STM-2I4.

Schatz, J. F., 1973. The Physics of SOC and TENSOR, Lawrence Livermore Laboratory, Livermore, CA 94550, UCRL-51352.

Schat7., J. F., 1974. SOC73, A Ome-Dimensional Wave Propagasion Code for Rock Media, Lawrence Livermore Laboratory, Livermorc, CA 94550, UCRL-51689.

Schatz, J. F., A. Kusubov, J. Hearst, A. Abey, C. Snell, and L. Thigpen, 1977. Rock Mechanics Project Progress and Results: Rock Fracture and Pore Collapse. Lawrence Livermore Laboratory, Livermore, CA 94550, UCID-17527.

Schwab, F. A. and L. Knoporf, 1972. Fast Surface Wave and Free Mode Computations, Methods in Comput. Phys.. 11. Academic Press, New York, 87-180.

Sharpe, 3. A., 1942. The Production of Elastic Waves By Explosion Pressures. I. Theory and Empirical Field Observations, Geophys., VII, 144-154.

Smith, W. D., 1975. The Application of Finite Element Analysis to Body Wave Propagation Problems, Geophys. J. R. Astr. Soc., 42, 747-678.

Sollogub, V. B. and A. V. Chekunov, Eds., 1978. Structure of the Earth's Crust and Upper Mantle Plorredfrom Data of Seismic Studies. Academy of Sciences of the Ukranian SSR, Institute of Geophysics, Naukova Dumka Publishers, Kiev, 1977, 308 pages. Lawrence Livermore Laboratory, Livermore, CA 94550. UCRL-TRANS-11392 (1978).

Springer, D. L., 1966a. Calculation of First-Zone P Wave Amplitudes for Salmon Event and Decoupled Sources, J. Geophy's. Res., 71, 3459-3467.

Springer, D. L., 1966b. P Wave Coupling of Underground Nuclear Explosions, Bull. Seismol. Soc. Am.. 56, 861-876.

Springer, D. L., M. Denny, J. Healy, and W. Mickey, 1968. The Sterling Experiment: Decoupling of Seismic Waves by a Shot Generated Cavity, J. Geophys. Res., 73, 5995.

Stump, B. W., and L. R. Johnson, 1977. The Determination of Source Properties by the Linear Inversion of Seismograms, Bull. Seismol. Soc. Am., 67, 1489-1502. 
Stoffa, P. L., P. Buhl, and G. M. Bryan, 1974. The Application of Homomorphic Deconvolution to ShallowWater Marine Seismolosy-Part I: Models, Geophys., 39, 401-416.

Swanger, H. J. and D. M. Boore, 1978. Simulation of Strong-Motion Displacements Using Surface-Wave Modal Superposition, Bull. Seismol. Soc. Am., 68, 907-922.

Takeuchi, H. and M. Saito, 1972. Seismic Surface Waves, Methods in Comput. Phys., 11, Academic Press, New York, 217-295.

Ulrych. T. J., 1971. Application of Homomorphic Deconvoiution to Seismology, Geophys., 36, 650-660.

Valyus, V. P., 1972. Determining Seismie Profiles from a Set of Observations, Computational Seismology, V. I. Keilis-Borok, Ed., translated from Russian by S. B. Dresner, translation edited by E. A. Flinn, Consultants Bureau, New York, 114-118.

Werth, G. C., R. F. Herbst, and D. L. Springer, 1962. Amplitudes of Seismic Arrivals from the M Discontinuity, J. Geophys. Res., 56, 1587-1610.

Werth, C., and R. F. Herbst, 1963. Comparison of Amplitudes of Seismic Waves from Nuclear Explosions in Four Mediums, J. Geophys. Res., 68, 1463-1475.

Weston, D. E., 1960. The Low-Frequency Scaling Laws and Source Levels for Underground Explosions and Other Disturbances, Geophys. J., 3, 191-202.

Wiggins, R, A., 1972. The General Linear Inverse Problem: Implications of Surface Waves and Free Oscillations for Earth Structure, Rev. Geophys. and Space Phys., 10, 251-285.

Wiggins, R. A. and D. V. Helmberger, 1973. Upper Mantle Structure of Western United States, J. Geophy's. Res., 78, 1869-1880.

Wiggins, R. and D. V. Helmberger, 1974. Synthetic Seismogram Computation by Expansion in Generalized Rays, Geophy's. J. R. Astr. Soc., 37, 73-90.

Wiggins, R. A. and J. A. Madrid, 1974. Body Wave Amplitude Calculations, Geophys. J. R. Astr. Soc., 37, 423-433.

Wiggins, R. A., 1976. Body Wave Amplitude Calculations-I1, Geophys. J. R. AsIr. Soc., 46, 1-10.

Ziv, M., 1969. Two-Spatial Dimensional Elastic Wave Propagation by the Theory of Characteristics, $/ n t . J$. Solids Structures, 5, 1135-1151.

Ziv, M., 1975a. A General Solution Method for Transient Multidimensional Problems in Solid Mechanics, Bull. Seismol. Soc. Am., 65, 1359-1384.

Ziv, M., 1975b. Transient Response of an Elassic Half-Space to an Embedded Cylindrical Load by a TwoSpatial Characteristic Computer Code. Dept. of Aeron. Eng., Technion-Israel Institute of Technology, TAE Report No. 250, U.S. Air Force Office of Scientific Research under Grant AFOSR 72-2330, AFOSRTR-1275, AD-A015866/7 G A, 188 pages.

Ziv, M., 1976. SBC Quarter-Plane Subjected to a Transient P-Wave and its Diffraction at Grazing Incidence, $J$. Acoust. Soc. Am., 60, 9-14.

Zvolinskii, N. V., 1960. On the Emission (Radiation) of an Elastic Wave from a Spherical Explosion in the Ground, $P M M, 24(1), 126-133$.

LG 